\title{
The Google Shortcut to Trademark Law
}

\author{
Lisa Larrimore Ouellette*
}

\begin{abstract}
Trademark distinctiveness - the extent to which consumers view a mark as identifying a particular source-is the key factual issue in assessing whether a mark is protectable and what the scope of that protection should be. But distinctiveness is difficult to evaluate in practice: assessments of "inherent distinctiveness" are highly subjective, survey evidence is expensive and unreliable, and other measures of "acquired distinctiveness" such as advertising spending are poor proxies for consumer perceptions. But there is now a simpler way to determine whether consumers associate a word or phrase with a certain product: Google. Through a study of trademark cases and contemporaneous search results, I argue that Google can generally capture both prongs of the test for trademark distinctiveness: If a mark is strong-either inherently distinctive or commercially strong - then many top search results for that mark relate to the source it identifies. The extent to which results overlap between searches for two different marks can also be relevant for assessing the likelihood of confusion between those marks. In the cases where Google and the court disagree, I argue that Google more accurately reflects how consumers view a given mark. Courts have generally given online search results little weight in offline trademark disputes. But the key factual questions in these cases depend on the wisdom of the crowds, making Google's "algorithmic authority" highly probative.
\end{abstract}

Copyright (C) 2014 California Law Review, Inc. California Law Review, Inc. (CLR) is a California nonprofit corporation. CLR and the authors are solely responsible for the content of their publications.

* Visiting Fellow, Yale Law School Information Society Project. Yale Law School, J.D. 2011; Cornell University, Ph.D. (Physics) 2008. This project was awarded the 2012 University of Houston Law Center IPIL Sponsored Scholarship Grant for Federal Appellate Clerks. For helpful feedback, sincere thanks to Ian Ayres, Jack Balkin, Barton Beebe, Adam Chandler, Tun-Jen Chiang, Victoria Cundiff, Anjali Dalal, Eric Goldman, Andrew Griffiths, James Grimmelmann, Daniel Hemel, Camilla Hrdy, Mark Lemley, Jessica Litman, Mark McKenna, Lisa Ramsey, Alexandra Roberts, Lea Shaver, Chris Sprigman, Rebecca Tushnet, Daniel Winik, and participants at the Oxford Workshop on Empirical Studies of Trade Mark Data, the Works-in-Progress Intellectual Property Conference at Seton Hall, a workshop at the Penn Law School Center for Technology, Innovation, and Competition, and the Northwestern Searle Center Research Roundtable on the Law and Economics of Digital Markets. 


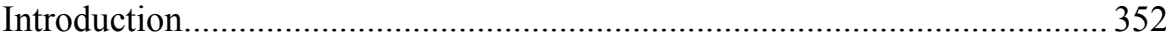

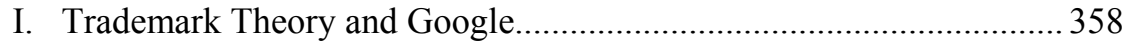

A. The Challenges of Adjudicating Trademark Disputes..................... 358

B. How Google Works and Why It Might Help .................................. 363

C. Judicial Justifications for Ignoring Search Results ........................... 369

II. Googling Trademarks: Empirical Results ............................................ 373

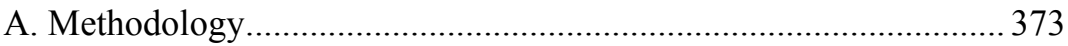

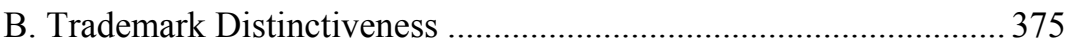

C. Likelihood of Confusion .............................................................. 380

D. When Do the Courts and Google Disagree? .................................. 384

1. When Google Goes Wrong .................................................... 384

2. Underestimating Trademark Strength .........................................386

3. Overestimating Trademark Strength ......................................... 391

4. Right on Strength, Wrong on Likelihood of Confusion............. 394

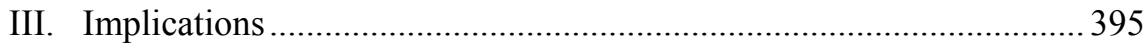

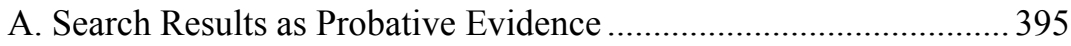

B. Using Google To Test New Marks ................................................. 399

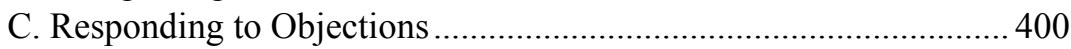

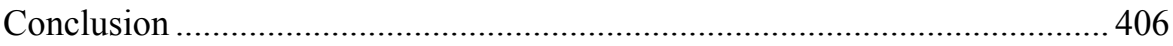

\section{INTRODUCTION}

Trademark law protects distinctive marks - those that identify the source of goods or services and distinguish those products from others in the marketplace. ${ }^{1}$ The "inherent distinctiveness" of a mark is its linguistic uniqueness for describing a product, and marks are classified-from most to least distinctive - as fanciful, arbitrary, suggestive, descriptive, or generic. ${ }^{2}$ Generic terms are never protectable, and descriptive terms are protectable only if they have "acquired distinctiveness" (also called "secondary meaning") such

1. See 15 U.S.C. § 1127 (2012) (defining "trademark" and "service mark" as words or designs used "to identify and distinguish" goods or services); Two Pesos, Inc. v. Taco Cabana, Inc., 505 U.S. 763,774 (1992) (stating that a purpose of trademarks is "to protect the ability of consumers to distinguish among competing producers" (emphasis added)); 2 J. THOMAS MCCARTHY, MCCARTHY ON TRADEMARKS AND UNFAIR COMPETITION § 11:2, at 11-5 (4th ed. 2013) ("If a designation is not 'distinctive,' it is not a 'mark."').

2. See Abercrombie \& Fitch Co. v. Hunting World, Inc., 537 F.2d 4, 9 (2d Cir. 1976) (Friendly, J.). The Supreme Court has approved of Judge Friendly's Abercrombie spectrum while (appropriately) separating his "arbitrary or fanciful" category into two categories. Two Pesos, 505 U.S. at 768. Fanciful marks are coined terms (such as KODAK); arbitrary marks are real words with no connection to the products they signify (such as APPLE computers); suggestive marks require imagination to link them to the product (such as COPPERTONE suntan lotion); descriptive marks describe some characteristic of the product (such as AMERICAN Airlines); and generic terms (which are never eligible for trademark protection) identify the class of products (such as "apple" for apples). See Abercrombie, 537 F.2d at 9-11 \& n.12. The Abercrombie spectrum is generally only appropriate for word marks, which are the focus of this Article. See 2 MCCARTHY, supra note 1, § 11:2. 
that buyers have come to view them as distinctive of a unique source. ${ }^{3}$ Whether a mark passes the distinctiveness threshold for validity is a binary yes-no question, but evaluating the strength of a mark-a critical issue in trademark infringement suits - requires evaluation of the degree of distinctiveness. Courts look again to the mark's placement on the inherent distinctiveness spectrum (to evaluate "conceptual strength") and to its acquired distinctiveness in the marketplace (to evaluate "commercial strength"), weighing these factors in a two-prong test. ${ }^{4}$

But courts often have difficulty applying these tests. The Second Circuit admits that "placing a mark in one of [the inherent distinctiveness]... categories is . . . a tricky business at best," and the Trademark Trial and Appeal Board ("TTAB") says this determination is "often made on an intuitive basis rather than as a result of precisely logical analysis." An empirical study found that courts often fail to apply the inherent distinctiveness spectrum at all. $^{7}$ Courts frequently lack the evidence to evaluate acquired distinctiveness properly: surveys are expensive and unreliable, and circumstantial evidence such as sales data and advertising spending are weak proxies for consumer perception. ${ }^{8}$

The complicated doctrines surrounding trademark distinctiveness are aimed at determining what products or services people associate with a mark. As McCarthy on Trademarks explains, "To an extent not true in other fields of law, in trademark and false advertising disputes the perceptions of large groups of ordinary people are key factual issues." What we need, in essence, is a simpler way to tell us whether consumers associate a mark with a certain product. Fortunately, we now have an easy way to do that: Google. ${ }^{10}$ This

3. See Two Pesos, 505 U.S. at 768-69. For example, consumers understand AMERICAN Airlines to be a particular airline company rather than merely descriptive of a U.S. airline. See 2 MCCARTHY, supra note $1, \S 11: 83$, at 11-232 (noting that AMERICAN Airlines has "recognition far beyond that minimum necessary for secondary meaning").

4. 2 MCCARTHY, supra note $1, \S 11: 83$.

5. Banff, Ltd. v. Federated Dep't Stores, Inc., 841 F.2d 486, 489 (2d Cir. 1988).

6. Anheuser-Busch, Inc. v. Holt, 92 U.S.P.Q.2d (BNA) 1101, 1105 (T.T.A.B. 2009). The leading trademark treatise agrees that these categories are often "difficult to distinguish" and that the descriptive-suggestive border is particularly "subjective" and based on "intuitive" determinations. 2 MCCARTHY, supra note $1, \S \S 11: 2,11: 70$.

7. Barton Beebe, An Empirical Study of the Multifactor Tests for Trademark Infringement, 94 CALIF. L. REV. 1581, 1635 (2006) ("'[O]nly 193 or 58\% of the 331 opinions sampled made some use of the Abercrombie spectrum, and twenty-nine of these opinions neglected to place the plaintiff's mark in one specific Abercrombie category."); see also Timothy Denny Greene \& Jeff Wilkerson, Understanding Trademark Strength, 16 STAN. TECH. L. REV. 535, 536 (2013) ("The doctrine of trademark strength is broken.").

8. See infra notes 51-59 and accompanying text.

9. 6 MCCARTHY, supra note $1, \S 32: 158$, at 32-335.

10. In practice one should compare results across multiple search engines, such as Bing and DuckDuckGo. I use "Google" as a convenient shorthand and as the platform for testing this method because of its market dominance. See infra notes 59-60 and accompanying text (discussing Google's 
Article presents a new empirical study of trademark cases based not on the doctrinal factors, but rather on Google results. ${ }^{11}$ Google dominates the web search market by being able to predict what people are thinking of when they type a word or phrase. ${ }^{12}$ Google results thus might be an accurate proxy for the distinctiveness of word marks. ${ }^{13}$

In particular, Google should be able to capture both parts of the two-prong test for trademark strength, as intuitively applied by the courts: if a mark is strong - either inherently distinctive or commercially strong - then the top Google hits should relate to that mark. For example, "FORD autos" and "PAYLESS shoe stores" are inherently weak marks that have become strong through their commercial strength (acquiring secondary meaning), ${ }^{14}$ and all the (unsponsored) links on the first page of Google results for [ FORD cars ] (as well as [ FORD ] alone) and [ PAYLESS shoes ] (as well as [ PAY LESS shoes ] ) are currently related to these brands. ${ }^{15}$ As discussed below, Google could also help adjudicate whether a mark has fallen victim to genericide, ${ }^{16}$ or whether a mark is sufficiently "famous" for antidilution protection. ${ }^{17}$

Search results might also have some probative value for assessing whether there is a "likelihood of confusion" between two marks, which is the standard for trademark infringement. ${ }^{18}$ Each circuit assesses confusion using its own

market position); Part III.0 (explaining that potential problems with relying on Google are overcome by comparing results with other search engines).

11. Previous scholarship on Google and trademarks has focused on the use of trademarks as search keywords or in advertisements, rather than on using organic search results as a tool to study trademarks. See, e.g., Dan L. Burk, Cybermarks, 94 MINN. L. REV. 1375 (2010); Greg Lastowka, Google's Law, 73 BROOK. L. REV. 1327 (2008); Tyson Smith, Googling a Trademark: A Comparative Look at Keyword Use in Internet Advertising, 46 TEX. INT'L L.J. 231 (2010).

12. See infra note 60 and accompanying text (discussing Google's market share).

13. While designs and trade dress are also protectable, this Article will focus on word marks. Advances in image search by Google or other companies, however, may make it possible someday to conduct a similar analysis on non-verbal marks. See Search by Image, GOOGLE, http://www.google .com/insidesearch/features/images/searchbyimage.html (last visited Jan. 2, 2014) (explaining how to begin a Google search with an image). But cf. Rebecca Tushnet, Looking at the Lanham Act: Images in Trademark and Advertising Law, 48 Hous. L. REV. 861 (2011) (describing the complexity of legal treatment of images).

14. See 2 MCCARTHY, supra note $1, \S 11: 83$.

15. In this Article, marks are indicated in all capital letters, and Google search queries are indicated within brackets and in a fixed-width font, following Google's practice. See, e.g., Search Operators, GOOGLE, http://support.google.com/websearch/bin/answer.py?hl=en\&answer=136861 (last visited Jan. 2, 2014). As discussed in more detail later, searches were performed in incognito mode in a Chrome browser with cookies cleared to avoid personalized search effects. See infra notes 122-23, 268-69 and accompanying text.

16. See 2 MCCARTHY, supra note $1, \S 12: 1$, at 12-9-10 ("[I]f one seller develops trademark rights in a term which a majority of the relevant public then appropriates as the name of a product, the mark is a victim of 'genericide' and trademark rights may cease.").

17. See 4 MCCARTHY, supra note $1, \S 24: 104$, at 24-324 ("The standard for the kind of 'fame' needed to trigger anti-dilution protection is more rigorous and demanding than the 'fame' which is sufficient for the classic likelihood of confusion test.").

18. See id. $\S 23: 1$. 
non-exhaustive test with as many as thirteen factors, such as the similarity of the marks, the proximity of the goods, evidence of actual confusion, and the strength of the plaintiff's mark. ${ }^{19}$ As one commentator stated, "Testing for likelihood of confusion is hardly a model of analytical rigor. ${ }^{20}$ In an empirical study of how these multifactor tests were applied in 331 likelihood-ofconfusion cases, Professor Barton Beebe concluded that "judges employ 'fast and frugal' heuristics to short-circuit the multifactor analysis." ${ }^{21} \mathrm{He}$ found that the similarity of the marks - i.e., the marks' relative distinctiveness from each other- "is by far the most important factor," although he also described it as a "frustratingly nebulous and unsystematic inquiry." 22 Google might help courts evaluate this factor: if searching for one mark yields results for the other source, this is some evidence that the marks are relatively less distinctive to consumers.

For example, AUDITORIO TELMEX (for "arena services") was refused registration in light of the prior mark TELMEX (owned by a Mexican telecommunications company), ${ }^{23}$ and everything on the first page of Google results for [ TELMEX ] is related to the telecommunications company, ${ }^{24}$ suggesting that consumers already have a strong association for TELMEX and that AUDITORIO TELMEX might be confusing. In contrast, Ritz Hotel was allowed to register RITZ for cooking and wine selection classes, even though RITZ was already registered for "kitchen textiles" such as dishtowels. ${ }^{25}$ The kitchen textiles company dominates the search results for [ RITZ towels ] and [ RITZ textiles ], confirming that it deserves trademark protection in these areas, but it does not appear on the first page of results for [ RITZ ] (which has links for Ritz hotels, Ritz Camera, Ritz crackers, etc.), [ RITZ cooking ], or [ RITZ wine ], ${ }^{26}$ suggesting that it is a comparatively weak mark and that consumers are not confused that the Ritz Hotel cooking and wine classes are related to the kitchen textiles company.

Part I of this Article explains why stronger reliance on Google might be normatively desirable, both under the dominant search-costs theory of

19. See id. \$\$ 24:30-43; see, e.g., In re E.I. DuPont DeNemours \& Co., 476 F.2d 1357, 1362 (C.C.P.A. 1973) (thirteen-factor test); Polaroid Corp. v. Polarad Elecs. Corp., 287 F.2d 492, 495 (2d Cir. 1961) (eight-factor test).

20. Graeme W. Austin, Tolerating Confusion About Confusion: Trademark Policies and Fair Use, 50 ARIZ. L. REV. 157, 169 (2008).

21. Beebe, supra note 7, at 1581; see also Kevin Blum et al., Consistency of Confusion? A Fifteen-Year Revisiting of Barton Beebe's Empirical Analysis of Multifactor Tests for Trademark Infringement, 2010 STAN. TECH. L. REV. 3, 36 (studying fifteen years of cases from the Southern District of New York and finding results that were generally "consistent with Beebe's national study").

22. Beebe, supra note 7, at 1623, 1625.

23. Estrada v. Telefonos De Mexico, S.A.B. de C.V., 447 F. App’x 197 (Fed. Cir. 2011).

24. Search performed on December 14, 2011, with location set to "United States."

25. Shen Mfg. Co. v. Ritz Hotel Ltd., 393 F.3d 1238, $1244-45$ (Fed. Cir. 2005).

26. Searches performed on December 14, 2011, with location set to "United States." 
trademark law and under alternative theories. As described in Part I.A, the multifactor tests for trademark scope and likelihood of confusion attempt to provide analytical rigor to the complicated question of how consumers perceive different marks, but empirical evidence shows courts apply these tests inconsistently and often disregard even survey evidence. Part I.B explains how Google results are effectively an unbiased survey of how a given search phrase is perceived, and how they might thus decrease the expense and increase the predictability of trademark disputes. Despite these advantages, search results, while admissible in trademark disputes, have thus far been given little evidentiary weight in traditional trademark infringement cases (as opposed to cases involving the use of trademarks online, such as in paid search-engine results, which are not the focus of this Article). ${ }^{27}$ Part I.C critiques courts' explanations for giving little weight to Google and other search-engine results.

Part II then describes the extent to which Google captures the results of actual trademark cases: I argue that Google often does a better job than the courts of evaluating factual issues of consumer perceptions. As explained in Part II.0, new federal trademark cases were tracked over a one-year period, and the results from these eighty-eight cases were compared with contemporaneous Google search results. As Part II.0 describes, in the majority of cases the court's assessment of the asserted mark's strength was correlated with the number of top Google results related to the source it identified-for strong marks, almost all of the top Google results were related to the associated product or service, while for weak or unprotectable marks, few of the top hits were related. Part II.0 shows that Google results on the relative distinctiveness of marks were also generally consistent with likelihood-of-confusion decisions - when searching for one party's mark resulted in hits that were solely related to the other party's product, courts were more likely to find a likelihood of confusion between the marks.

In a minority of cases, however, the court reached a conclusion that seems inconsistent with this "Google shortcut" to trademark disputes, and Part II.0 examines these cases in detail. A few cases illustrate that even when Google accurately represents how consumers perceive the marks at issue, judicial wisdom is still necessary to interpret these facts under the relevant legal regime. In general, however, where the court and Google disagree, I argue that the court got it wrong: Google does a better job of reflecting how consumers perceive a given word or phrase than the heuristics courts typically employ. In this sense, the Google shortcut is not simply a way to gain efficiency at the expense of accuracy, as one might expect if courts regularly had access to high-

27. Although the Federal Circuit has agreed with a 2006 TTAB decision stating that a "list of internet search results is "not given much weight," In re Bayer Aktiengesellschaft, 488 F.3d 960, 967 (Fed. Cir. 2007) (quoting In re King Koil Licensing Co., 79 U.S.P.Q.2d (BNA) 1048, 1050 (T.T.A.B. 2006)), the TTAB has become more receptive to search-engine evidence than the courts. See infra notes 261-62 and accompanying text. 
quality consumer surveys. Rather, it is a more accurate and direct route to get the factual answers courts seek about how customers actually perceive marks.

To be sure, as discussed further below, trademark cases cannot be objectively measured for the correct result, so it cannot be proven that the Google shortcut is objectively better-but I argue that an understanding of how Google works coupled with these examples provide convincing evidence that Google evidence is highly probative. Interestingly, while the courts were somewhat more likely to underestimate trademark strength than to overestimate it (relative to Google), overestimations of strength were much more likely than underestimations to lead to a finding of likelihood of confusion that was inconsistent with the Google results. This suggests that courts may be finding confusion too often - which is consistent with the normative views of many trademark scholars.

Finally, Part III examines the implications of this study. Part III.0 discusses how parties and courts might use Google and other search-engine results in practice. Part III.0 explores whether these results could be extended to testing new trademarks that are not yet being used in commerce. Lastly, Part III.0 responds to potential objections to the Google shortcut. For example, some might be concerned about giving power over key factual determinations to Google results given Google's lack of transparency about its search methods, the influence of personalized search results, and the possibility of "gaming" Google results using search-engine optimization. But many of these concerns do not apply to the kinds of searches that would be relevant in trademark cases, and, in any case, Google currently manages to find what the average searcher is looking for despite enormous incentives on the part of companies to skew Google results. These concerns would also be alleviated if parties could demonstrate that the search results are consistent over time and across multiple search engines. If Google loses its dominant position because another search engine does a better job of accurately linking search terms with related products, then courts and litigants should adjust accordingly.

Furthermore, I am not advocating for Google-based robot judges. Google helps address disputed factual questions about consumer perceptions, but disputes of law remain for the court. Judicial wisdom is necessary to evaluate factors that Google's search algorithms cannot measure, including whether a word is being used as a mark, priority of use, the defendant's intent in selecting a mark, and whether recognizing rights in a mark would impinge on the values of free speech and competition. My claim is simply that Google results are highly probative of the validity and strength of a mark and (to a lesser extent) its similarity to another mark, and that judges should thus encourage searchengine evidence - or take judicial notice of their own Google searches ${ }^{28}$ - and grant more weight to this evidence when resolving trademark disputes. The

28. See infra note 259 and accompanying text. 
Google shortcut is far from perfect, but it is a valuable addition to the trademark evidence courts currently consider, and its downsides are no worse than those of the evidence that courts currently use to resolve trademark disputes.

I.

\section{TRADEMARK THEORY AND GOOGLE}

\section{A. The Challenges of Adjudicating Trademark Disputes}

The dominant theoretical account of trademark law is the economic theory that trademarks minimize consumer search costs by preventing parties from using marks likely to confuse consumers as to the source of particular goods or services. ${ }^{29}$ Professor Mark McKenna has argued that this focus on search costs has led to an unwarranted concern with all types of confusion, and that trademark law should only be concerned with confusion that actually affects consumer decision making. ${ }^{30}$ Professor Barton Beebe has argued that these economic theories should be supplemented by a "semiotic" account that considers consumers" demand for "signs, distinctions, differences." ${ }^{31}$ McCarthy on Trademarks notes that protection of the trademark holder's property right is another important goal of trademark law. ${ }^{32}$ Professor Robert Bone argues that these economic concerns should be treated separately from moral arguments such as intentional deception. ${ }^{33}$ Others suggest that trademark law should focus more heavily on other values, such as the First Amendment ${ }^{34}$ or consumer autonomy. ${ }^{35}$

Under all of these theories, however - and as a matter of positive law-a judge facing a trademark infringement claim must evaluate trademark

29. See Mark P. McKenna, A Consumer Decision-Making Theory of Trademark Law, 98 VA. L. ReV. 67, 73-76 \& n.14 (2012) (citing William M. Landes \& Richard A. Posner, Trademark Law: An Economic Perspective, 30 J.L. \& ECON. 265, 265-69 (1987)); see also Qualitex Co. v. Jacobson Prods. Co., 514 U.S. 159, 163-64 (1995) ("[T]rademark law ... 'reduce[s] the customer's costs of shopping and making purchasing decisions'....”).

30. McKenna, supra note 29.

31. Barton Beebe, The Semiotic Account of Trademark Doctrine and Trademark Culture, in TRADEMARK LAW AND THEORY: A HANDBOOK OF CONTEMPORARY RESEARCH 42, 64 (Graeme B. Dinwoodie \& Mark D. Janis eds., 2008) [hereinafter Beebe, Semiotic Account]; see Barton Beebe, The Semiotic Analysis of Trademark Law, 51 UCLA L. REV. 621 (2004).

32. 1 MCCARTHY, supra note $1, \S 2: 1$.

33. Robert G. Bone, Taking the Confusion out of "Likelihood of Confusion": Toward a More Sensible Approach to Trademark Infringement, 106 Nw. U. L. REV. 1307, 1377 (2012).

34. See Lisa P. Ramsey, Increasing First Amendment Scrutiny of Trademark Law, 61 SMU L. REV. 381 (2008) (arguing for increased First Amendment scrutiny to prevent trademark laws from chilling protected speech); Rebecca Tushnet, Trademark Law as Commercial Speech Regulation, 58 S.C. L. REV. 737, 756 (2007) (arguing that while she is "largely in favor of core trademark infringement doctrine as it stands now," trademark law should be treated more consistently with other commercial speech for First Amendment purposes).

35. See Laura A. Heymann, The Public's Domain in Trademark Law: A First Amendment Theory of the Consumer, 43 GA. L. REV. 651 (2009). 
distinctiveness. Distinctiveness is essential for determining whether the plaintiff's mark is protectable (such as whether a descriptive mark has secondary meaning) and also for determining what the scope of that protection should be (i.e., the strength of the mark). A judge must also evaluate how distinct from each other the marks at issue are in determining whether the allegedly infringing mark creates confusion within the scope of protection for the plaintiff's mark. Trademark scholars might disagree about what the court should focus on next: whether any confusion raises consumer search costs, whether it deceives consumers in their decision making, or whether it creates other harms. But an understanding of the factual issue of distinctiveness is a predicate to applying any of these theories.

Beebe's empirical study found that when courts currently evaluate trademark distinctiveness, "[b]asic concepts are no longer consistently applied and mistakes of doctrine are common." ${ }^{36}$ As described in the Introduction, the strength of a trademark is determined by weighing inherent distinctiveness - its placement on Judge Friendly's Abercrombie spectrum ${ }^{37}$-with acquired distinctiveness or commercial strength. ${ }^{38}$ The Second Circuit has acknowledged that placing a mark along the Abercrombie spectrum "is far from an exact science, and that the differences between the classes, which is not always readily apparent, makes placing a mark in its proper context and attaching to it one of the [Abercrombie] labels a tricky business at best." ${ }^{, 39}$ A number of courts and the TTAB have agreed with the Seventh Circuit that the distinction between a descriptive mark (which requires secondary meaning to be protected) and a suggestive mark (which does not) is often made on an "intuitive basis" rather than through "logical analysis." Similarly, McCarthy on Trademarks states that the Abercrombie categories are often "difficult to distinguish" and that the descriptive-suggestive border is particularly "subjective" and based on "intuitive" determinations. ${ }^{41}$

In practice, however, Beebe's study shows that these subtle distinctions between Abercrombie categories do not matter much because the spectrum "has broken down"- courts failed to place the plaintiff's mark in a specific category in half of the cases in his dataset. ${ }^{42}$ As a normative matter, Beebe has persuasively argued that the Abercrombie spectrum should be abandoned for

36. Beebe, supra note 7, at 1633 .

37. Abercrombie \& Fitch Co. v. Hunting World, Inc., 537 F.2d 4, 9 (2d Cir. 1976) (classifying marks, from least to most distinctive, as generic, descriptive, suggestive, arbitrary, or fanciful).

38. See 2 MCCARTHY, supra note $1, \S 11: 83$.

39. Banff, Ltd. v. Federated Dep't Stores, Inc., 841 F.2d 486, 489 (2d Cir. 1988).

40. Union Carbide Corp. v. Ever-Ready Inc., 531 F.2d 366, 379 (7th Cir. 1976) (quoted for this statement by the Third, Fourth, and Ninth Circuits, as well as by numerous district courts); see Anheuser-Busch, Inc. v. Holt, 92 U.S.P.Q.2d (BNA) 1101, 1105 (T.T.A.B. 2009).

41. 2 MCCARTHY, supra note $1, \S \S 11: 2,11: 70$.

42. Beebe, supra note 7, at 1633-35 (stating that some use of the spectrum was made in only 193 out of 331 cases and that the mark was placed in a specific category in only 164 cases). 
determining whether a mark is protectable: "All that matters is whether, for a sufficient proportion of the relevant consumer population, the mark is or is not distinctive of source," not whether the mark is suggestive or descriptive or whether its distinctiveness is inherent or applied. ${ }^{43}$ And for determining the scope of protection, what matters is "the degree to which the mark actually stands out from the noise of the marketplace." 44 Professor Ann Bartow has similarly argued that although judges often categorize trademarks based on their "internal visceral impressions," distinctiveness is context specific and should be based on "consumer understanding and common usage of the term at the time the issue is presented to a court." ${ }^{.45}$ And a recent empirical study by Professor Thomas Lee and colleagues shows that the actual use of a hypothetical mark (such as placement and font size) matters more than its position on the Abercrombie spectrum for whether consumers view the mark as source-indicating. ${ }^{46}$ The Abercrombie spectrum might still serve other valuesfor example, trademark rights in generic or descriptive terms can chill speechbut these values should not be confused with the factual issue of whether consumers view a mark as distinguishing a particular source.

The complex doctrine that has evolved around trademark strength and likelihood of confusion appears to be a (largely unsuccessful) attempt to provide some analytical rigor to the essential questions of how strongly a mark identifies goods or services and how well it distinguishes those products from others in the marketplace. ${ }^{47}$ The answer to these questions depends on the subjective "perceptions of large groups of ordinary people." 48 In other words, to a greater extent than in other areas of law, trademark disputes turn on the wisdom of the crowds, not expert judgment.

In an attempt to gauge this public perception, courts often turn to survey evidence in trademark disputes. ${ }^{49}$ As explained by Professor Irina Manta, while "the mindset of actual or potential customers" is "critical," well-done surveys that tap into "subconscious cognitive processes" are necessary because "[m]ost direct questions would either bias or confuse the customer., ${ }^{, 50}$ But courts ${ }^{51}$ and

43. Beebe, Semiotic Account, supra note 31, at 55-56.

44. Id. at 56; see also Greene \& Wilkerson, supra note 7, at 537 ("[W] hat matters most is how consumers in the marketplace react to the mark.").

45. Ann Bartow, Likelihood of Confusion, 41 SAN DiEGO L. REV. 721, 738-43 (2004).

46. Thomas R. Lee, Eric D. DeRosia \& Glenn L. Christensen, An Empirical and Consumer Psychology Analysis of Trademark Distinctiveness, 41 ARIZ. ST. L.J. 1033 (2009).

47. See 15 U.S.C. $§ 1127$ (2012) (defining "trademark" and "service mark" as words or designs used "to identify and distinguish" goods or services); 1 MCCARTHY, supra note 1, $\S 3: 1$ (stating that this was also the definition of trademarks at common law). The Supreme Court has noted that a purpose of trademarks is "to protect the ability of consumers to distinguish among competing producers.” Two Pesos, Inc. v. Taco Cabana, Inc., 505 U.S. 763, 774 (1992) (emphasis added).

48. 6 MCCARTHY, supra note $1, \S 32: 158$, at 32-335.

49. See id.

50. Irina D. Manta, In Search of Validity: A New Model for the Content and Procedural Treatment of Trademark Infringement Surveys, 24 CARDOZO ARTS \& ENT. L.J. 1027, 1036 (2007). 
commentators ${ }^{52}$ note that surveys are often unreliable and expensive. Indeed, surveys can cost hundreds of thousands of dollars. ${ }^{53}$ Because of this cost, the Restatement (Third) of Unfair Competition states that no adverse inference should be drawn from the failure to offer survey evidence. ${ }^{54}$ In fact, Beebe's empirical study found that "the conventional view of the utility of survey evidence may be incorrect": only 20 percent of the cases he reviewed addressed survey evidence, 10 percent credited survey evidence, and 7 percent ruled in favor of the outcome that the credited survey evidence favored. ${ }^{55}$ These results support Professor McCarthy's suggestion that the inexact science of assessing

51. Nabisco, Inc. v. PF Brands, Inc., 191 F.3d 208, 224 (2d Cir. 1999) ("[C]onsumer surveys ... are expensive, time-consuming and not immune to manipulation."), abrogated on other grounds by Moseley v. V Secret Catalogue, Inc., 537 U.S. 418, 434 (2003) (noting that dilution surveys might be "expensive" and "unreliable"); Johnson v. Revenue Mgmt. Corp., 169 F.3d 1057, 1063 (7th Cir. 1999) (Eschbach, J., concurring) ("[S]urvey evidence in trademark and trade dress cases can be very costly."). For a discussion of potential empirical problems with survey evidence from the Federal Judicial Center, see generally Shari Seidman Diamond, Reference Guide on Survey Research, in Fed. Judicial Ctr., RefERENCE MANUAL On SCIENTIFIC EVIDENCE 359 (3d ed. 2011).

52. Robert C. Bird \& Joel H. Steckel, The Role of Consumer Surveys in Trademark Infringement: Empirical Evidence from the Federal Courts, 14 U. PA. J. BUS. L. 1013, 1017 \& n.20 (2012) (reviewing sources showing that "[c]onsumer surveys are expensive to create and time consuming to administer"); Robert G. Bone, Enforcement Costs and Trademark Puzzles, 90 VA. L. REV. 2099, 2131 (2004) ("Consumer surveys are the best evidence of secondary meaning, but surveys are difficult to design properly and expensive to conduct. . . . Judges also find it difficult to evaluate survey methodology, especially when confronted with competing expert testimony, and this increases the likelihood of error."); Manta, supra note 50 (describing the inconsistencies in courts' treatment of surveys and proposing substantive guidelines for survey admissibility); Robert H. Thornburg, Trademark Surveys: Development of Computer-Based Survey Methods, 4 J. MARSHALL REV. INTELL. PROP. L. 91, 91 (2004) (explaining that traditional trademark surveys have "prices ranging in the hundreds of thousands of dollars" and "are all subject to being discredited and devalued" due to procedural flaws); Rebecca Tushnet, Running the Gamut from A to B: Federal Trademark and False Advertising Law, 159 U. PA. L. REV. 1305, 1340 \& n.138 (2011) (citing additional sources).

53. Robert H. Thornburg, Trademark Survey Evidence: Review of Current Trends in the Ninth Circuit, 21 SANTA Clara COMPUTER \& High TeCH. L.J. 715, 717 (2005) ("[T]he most basic of surveys cost[s] in the hundreds of thousands of dollars."); E-mail from Jacob Jacoby, Professor, NYU Stern School of Business, to Lisa Larrimore Ouellette, Fellow, Yale Law School Information Society Project (Feb. 28, 2013, 7:20 PM) (on file with author) ("I would say that the typical trademark survey costs between $\$ 75,000$ and $\$ 150,000$. . . Some can be done for less; others will cost more.”). For an empirical comparison of different survey formats, including more cost-effective online surveys, see Hal Poret, A Comparative Empirical Analysis of Online Versus Mall and Phone Methodologies for Trademark Surveys, 100 TRADEMARK REP. 756 (2010).

54. See Restatement (ThiRD) OF UNFAIR COMPETITION $§ 23 \mathrm{cmt}$ c c (1995) ("Although surveys can be helpful in resolving the issue of infringement, they can also add significantly to the cost of trademark litigation. While some courts have drawn adverse inferences against parties who fail to introduce a consumer survey, such an approach attributes too much importance to survey evidence."). Some courts draw an adverse inference anyway, although this approach has been criticized. See Sandra Edelman, Failure to Conduct a Survey in Trademark Infringement Cases: A Critique of the Adverse Inference, 90 TRADEMARK REP. 746 (2000); 6 MCCARTHY, supra note 1, § 32:195-196.

55. Beebe, supra note 7, at 1641. A more recent study that expanded Beebe's dataset found that only 17 percent of cases addressed survey evidence. See Bird \& Steckel, supra note 52, at 1035. 
trademark strength causes judges to rely upon or reject surveys based on whether the results agree with their own subjective impressions. ${ }^{56}$

When direct evidence from surveys (or unrepresentative consumer testimony) is unavailable or unreliable, courts can evaluate trademark strength and secondary meaning only through circumstantial evidence such as sales volume and advertising expenditures. ${ }^{57}$ But these factors are weak proxies for consumer perceptions, and courts often discount this evidence by concluding that it does not indicate the necessary association in consumers' minds between the mark and the product or service. ${ }^{58}$ As with surveys, there is little for judges to rely on in determining whether to credit this evidence besides their own intuition.

But there is little reason to expect that individual judges are particularly good at gauging public perception of a mark, especially given the significant demographic differences between the average judge and the relevant population of consumers in most cases. Ideally, each judge faced with a trademark dispute would have access to an unbiased, high-quality survey of how consumers perceive the marks at issue. Commissioning an independent survey for each case would be prohibitively expensive, but parties and judges already have access to a powerful tool for determining what consumers associate with a given word or phrase: Google.

56. 6 MCCARTHY, supra note $1, \S 32: 196$ ("Since an estimation of the probable mental reactions and associations of the buying public is not a science, there is always the temptation to decide on the basis of a 'hunch.' That is, the trier of fact (or any human being) would rather extrapolate from his or her own subjective impressions than extrapolate from some hard evidence of other persons' subjective impressions - especially if the two do not agree.”); see also Peter Weiss, The Use of Survey Evidence in Trademark Litigation: Science, Art or Confidence Game?, 80 TRADEMARK REP. 71, 83 (1990) ("[A] reading of the many cases in which either great weight or little weight was given to survey evidence will, I feel reasonably certain, lead most objective analysts to the conclusion that, while some surveys went down because they were indeed 'seriously flawed,' many others either stayed up or went down depending on the result which the judges wanted to reach.").

57. 2 MCCARTHY, supra note $1, \S \S 11: 83,15: 30$.

58. See, e.g., Int'l Jensen, Inc. v. Metrosound U.S.A., Inc., 4 F.3d 819, 824 (9th Cir. 1993) ("While evidence of a manufacturer's sales, advertising and promotional activities may be relevant in determining secondary meaning, the true test of secondary meaning is the effectiveness of this effort to create it."); Walt-W. Enters., Inc. v. Gannett Co., 695 F.2d 1050, 1060 (7th Cir. 1982) (“The facts that [plaintiff] used the term for ten years and spent large sums of money in advertisements containing the term are simply not germane unless it can show that the way in which it employed the term dispelled the tendency of listeners to regard the term as [descriptive] and instead regard the primary significance of the term as designating a single ... source . ...”); Adidas-Am., Inc. v. Payless Shoesource, Inc., 546 F. Supp. 2d 1029, 1086 (D. Or. 2008) ("[E]vidence of extensive sales or product popularity is not necessarily indicative of secondary meaning. Such evidence can be attributed to 'dozens of factors, only one of which may be the drawing power of the trademark."') (quoting 2 MCCARTHY, supra note $1, \S 15: 47$ ); see also 2 MCCARTHY, supra note $1, \S 15: 48$ ("It has often been noted by the courts that evidence of plaintiff's advertising efforts does not automatically lead to the inference that the advertising has been effective in creating secondary meaning."). 


\section{B. How Google Works and Why It Might Help}

This Article focuses on Google only because of its current dominant market position. ${ }^{59}$ Google dominates the web search market, both in the United States and internationally, ${ }^{60}$ by generally being able to predict what online content consumers associate with a search term-effectively operating as an inexpensive and neutral survey. The exact algorithm used to produce Google results is a complex trade secret, which Google describes as follows:

Today our algorithms rely on more than 200 unique signals, some of which you'd expect, like how often the search terms occur on the webpage, if they appear in the title or whether synonyms of the search terms occur on the page. Google has invented many innovations in search to improve the answers you find. The first and most well known is PageRank, ... [which] works by counting the number and quality of links to a page to determine a rough estimate of how important the website is. The underlying assumption is that more important websites are likely to receive more links from other websites. ${ }^{61}$

In essence, a link to a site counts as a vote for that site, and votes are weighted based on the importance of the linking site - a site's search ranking will be boosted more by a link from the New York Times website than by a link from John Doe's Myspace page. But "spam" site operators can exploit the PageRank algorithm to promote irrelevant sites, so Google frequently tweaks its search algorithm (including 516 times in 2010) in an effort "to return only the most relevant results at the top of the page" so that "searchers click the new \#1 result more often." 62

For example, Google has downgraded the weight of votes from websites that simply insert irrelevant links into recycled content from other sources. ${ }^{63}$ Google explains that it is searching for "natural links," which "develop as part of the dynamic nature of the web when other sites find your content valuable and think it would be helpful for their visitors," as opposed to links placed

59. As discussed further in Part III, parties offering Google evidence should demonstrate whether the search results are consistent across multiple search engines, and if another search engine eventually outperforms Google at linking search terms with products, courts should assign less weight to Google evidence.

60. See Danny Goodwin, Google Smashes U.S. Search Market Share Record, Closes in on 70\%, SEARCH ENGINE WATCH (Nov. 21, 2012), http://searchenginewatch.com/article/2226212 /Google-Smashes-U.S.-Search-Market-Share-Record-Closes-in-on-70; Search Engine Market Share, NETMARKETSHARE, http://www.netmarketshare.com/search-engine-market-share.aspx?qprid=4\&qp $\mathrm{mr}=100 \& q p c t=3 \& q p t i m e f r a m e=Y$ (last visited Nov. 25, 2012) (reporting that Google has about 80 percent of the global search market).

61. Facts About Google and Competition, GOOGLE, http://www.google.com/competition /howgooglesearchworks.html (last visited Jan. 2, 2014).

62. Id.

63. Matt Cutts, Another Step To Reward High-Quality Sites, GOOGLE InSIDE SEARCH (Apr. 24, 2012, 2:45 PM), http://insidesearch.blogspot.com/2012/04/another-step-to-reward-highquality.html (giving examples of irrelevant links such as "Climbing is a terrific way to stay fit while not having to expend every day fast cash loans a health club."). 
[Vol. 102:351

"specifically to make your site look more popular to search engines." ${ }^{\text {64 }}$ Google also considers whether users quickly return to Google after clicking on a result ${ }^{65}$ or whether users have asked for a site to be blocked from their search results. ${ }^{66}$

Google has also changed its algorithm to improve its linguistic understanding, as explained in a 2010 Wired exclusive:

Google's synonym system understood that a dog was similar to a puppy and that boiling water was hot. But it also concluded that a hot dog was the same as a boiling puppy. The problem was fixed in late 2002 by a breakthrough based on philosopher Ludwig Wittgenstein's theories about how words are defined by context. As Google crawled and archived billions of documents and Web pages, it analyzed what words were close to each other. "Hot dog" would be found in searches that also contained "bread" and "mustard" and "baseball games"- not poached pooches. That helped the algorithm understand what "hot dog"-and millions of other terms - meant. "Today, if you type 'Gandhi bio,' we know that bio means biography," [a Google engineer] says. "And if you type 'bio warfare,' it means biological.",67

Google has also focused on improving its ability to parse searches-for example, to realize that [ mike siwek lawyer $\mathrm{mi}$ ] is searching for an attorney in Michigan named Michael Siwek. As explained by a Google engineer, "The holy grail of search is to understand what the user wants .... Then you are not matching words; you are actually trying to match meaning.",68 The Wired reporter extolled Google's "seemingly magical ability to interpret searchers' requests - no matter how awkward or misspelled," but also noted that competitors such as Microsoft's Bing search engine "aren't ready to concede defeat." 69 Two years later, in 2012, a Bing employee told another Wired reporter that "if you look at Google and Bing, the quality is beginning to be very comparable." 70

Because a single search can depend on hundreds of factors and links between millions of websites, even someone with full access to Google's algorithm could not provide a simple explanation for a given set of search

64. Google-Friendly Sites, GOOGLE, http://support.google.com/webmasters/bin/answer.py?hl $=$ en\&answer $=40349$ (last visited Jan. 2, 2014).

65. See Tom Gregan, 10 Things You Need To Know About Google Panda and Penguin, .NET (June 18, 2012), http://www.netmagazine.com/features/10-things-you-need-know-about-google-panda -and-penguin.

66. See Amit Singhal, High-Quality Sites Algorithm Goes Global, Incorporates User Feedback, GOOGLE WeBMASTER CENTRAL BLOG (Apr. 11, 2011, 12:00 PM), http://googlewebmaster central.blogspot.com/2011/04/high-quality-sites-algorithm-goes.html.

67. Steven Levy, Exclusive: How Google's Algorithm Rules the Web, WIRED (Feb. 22, 2010, 12:00 PM), http://www.wired.com/magazine/2010/02/ff_google_algorithm/all.

68. Id.

69. Id.

70. Cade Metz, Microsoft Says Decaffeinated Bing Tastes as Good as Google, WIRED (Mar. 8, 2012, 6:30 AM), http://www.wired.com/wiredenterprise/2012/03/microsoft-bing-v-google/all. 
results. But to provide a rough understanding, the sites linking to payless.com (and driving it to the first hit for searches including [ PAYLESS ] and [ PAY LESS ] ) include mall directories, ${ }^{71}$ news stories about Payless, ${ }^{72}$ a list of recommended footwear available at Payless for patients with a neurological syndrome, ${ }^{73}$ and fashion blogs describing Payless shoes. ${ }^{74}$ Without the context of Google's ranking, each of these websites would provide some evidence that consumers associate "pay less" with the shoe store, but it is easy to find contrary evidence of websites that use the phrase "pay less" in a descriptive sense. ${ }^{75}$ A court presented with ten websites using "pay less" or "payless" descriptively and ten websites referring to the shoe store could not evaluate how the average consumer views the phrase. The advantage of Google is that it in essence allows courts to survey the millions of websites using "pay less" and to see that consumers searching for [ PAY LESS shoes ] are generally looking for Payless the store, rather than for sites about how to pay less money for shoes. ${ }^{76}$ In other words, the Google search results are evidence that PAYLESS has acquired secondary meaning and that it has become a strong mark.

Google can also help courts understand how consumers view misspellings and synonyms - such as the difference between "payless" and the descriptive

71. See, e.g., Directory, QUEENS CTR., http://www.shopqueenscenter.com/map (last visited Jan. 2, 2014).

72. See, e.g., Emma Grady, Payless To Launch Green Footwear with Zoe \& Zac and Summer Rayne Oakes, TREEHUGGER (Nov. 18, 2008), http://www.treehugger.com/style/payless-to-launch -green-footwear-with-zoe-zac-and-summer-rayne-oakes.html.

73. Resources, REFLEX SyMPATHETIC DYSTROPHY SyNDROME ASS'N (Dec. 14, 2009), http://www.rsds.org/4/resources/Footwear_survey.html.

74. See, e.g., Mandiferous7, Wide Calf Boots-Rory Slouch Boot at Payless, FATSHIONISTA (Aug. 31, 2012, 11:28 AM), http://fatshionista.livejournal.com/7497670.html ("I just picked up a pair of Rory Slouch Boots at Payless and wanted to share the good news that they fit large calves!'); Heather Ward, Tuesday's Threads, THE CURVY LIFE (Oct. 30, 2012, 10:09 AM), http://thecurvylife 2011.blogspot.com/2012/10/tuesdays-threads_30.html ("I got these adorbs boots at Payless! I have been searching and searching and searching for some light brown boots and my fat calves prevented me from buying every pair I loved! I tried these on and to my amazement and joy they fit! Here's the link to Payless.com where you can buy them! They were only $\$ 60$. Not bad for boots!”).

75. For example, the query [ "pay less than" shoes -payless ] searches for sites that contain the phrase "pay less than" and the word "shoes," but that do not contain the word "payless." Results include the website for Red's Shoe Barn, which states that "you'll pay less than other shoe stores, with our everyday discount pricing," Men \& Womens Comfort Shoes NH, RED’s SHOE BARN, http://redsshoebarn.com/footwear/comfort (last visited Jan. 2, 2014), and a blog that touts the ability to "pay less than half what I'd pay at the local running store" at an online shop, Cherl, Buying Shoes and Gear Online, MARATHON MOMMIES (Mar. 13, 2011, 9:50 PM), http://marathon mommies.blogspot.com/2011/03/buying-shoes-and-gear-online.html.

76. I infer this because at least the top one hundred results for [ PAY LESS shoes ] (in a search performed on January 13, 2013, with search location set to "United States") use "pay less" in this manner, rather than descriptively. Of course, it is possible that some of these consumers were initially looking for a site describing how to pay less for shoes and only discovered Payless the store after searching, but if most searchers were really looking for a site that uses "pay less" descriptively, such a site would likely be in the first page of Google results. 
"pay less." $" 77$ Under trademark doctrine, misspellings enhance a mark's distinctiveness only if they change its significance to the buyer, ${ }^{78}$ but understanding how significant a misspelling is solely through linguistic theorizing is challenging. Google is able to illustrate the actual importance of a misspelling to consumers.

Using Google to evaluate how consumers view PAYLESS does not require an understanding of what consumers are actually searching for. As Professor Eric Goldman has explained, searches are hard to interpret - someone searching for [ PAYLESS ] might want shoe reviews, comparisons with other shoe stores, pricing information, general investor or other news, or a "gripe site" such as http://payless-shoesource.pissedconsumer.com. ${ }^{79}$ But all of these sites equivalently count as using "Payless" to refer to the shoe company-including the site for a competing shoe company that explains why it is better than Payless - and they are thus equivalent for evaluating PAYLESS's strength as a source indicator.

Evaluating PAYLESS as a mark also does not require a detailed understanding of Google's search algorithm. ${ }^{80}$ The key fact is that Google has a profit motive to order results based on relevance to consumers - such that users generally find what they are looking for on the first page of results- so that it can continue to sell those consumers' eyeballs to advertisers. ${ }^{81}$ How one then uses Google results to evaluate trademarks might depend on that person's underlying theory of trademark law: for example, those concerned about search

77. Cf. Levy, supra note 67 (describing how Google interprets misspellings and synonyms).

78. See 2 MCCARTHY, supra note $1, \S 11: 31$, at 11-84 ("If the misspelling is so phonetically identical to the original descriptive term that buyers will recognize it as descriptive, then the misspelled mark is still 'descriptive."); $i d . \S 12: 38$ ("[A] misspelling of a generic name which does not change the generic significance to the buyer[] is still generic.").

79. See Eric Goldman, Deregulating Relevancy in Internet Trademark Law, 54 EMORY L.J. 507,523 (2005) (describing a range of possible motivations behind a search for "Canon"). Because of the importance of these unofficial uses of trademarks for finding relevant information about a product, I strongly agree with Goldman that "it is important for trademark law to foster, not squelch, online word of mouth." Eric Goldman, Online Word of Mouth and Its Implications for Trademark Law, in TRADEMARK LAW AND THEORY: A HANDBOOK OF CONTEMPORARY RESEARCH, supra note 31, at 404, 405.

80. For further discussion of Google's black box search algorithm, including the influence of personalized search and gaming through search-engine optimization, see infra Part III.0.

81. See Meghan Kelly, 96 Percent of Google's Revenue Is Advertising, Who Buys It?, VENTURE BEAT (Jan. 29, 2012, 4:38 PM), http://venturebeat.com/2012/01/29/google-advertising. Even though my study looks at organic results, not paid results, advertisers still want Google to provide relevant organic results to maintain its large user base. See Kristine Laudadio Devine, Preserving Competition in Multi-Sided Innovative Markets: How Do You Solve a Problem Like Google?, 10 N.C. J.L. \& TECH. 59, 74 (2008) ("For advertisers, the greatest value comes from buying advertising on the search engine with the most users and the best results . . . . Google leads in both of these categories."). Of course, Google's placement in a two-sided market (serving both searchers and advertisers) raises special concerns about lock-in effects that may deserve antitrust scrutiny. See id. at 78-89; see also Frank Pasquale, Restoring Transparency to Automated Authority, 9 J. TELECOMM. \& High TECH. L. 235, 247 (2011) (proposing Federal Trade Commission oversight of search-engine practices). 
costs might be interested in how difficult it is to find a product, while those concerned about protecting speech might be hesitant to find a descriptive mark protectable if even a few of the top search results use the mark descriptively rather than as a source identifier. But knowing what consumers are looking for when they search for a mark is useful evidence for applying any of these theories.

The ability of Google to link marks with goods and services does not require that the company or product at issue have its own website. Small businesses without their own websites, such as food trucks, dry cleaners, and corner groceries, generally will still have reviews on sites such as Yelp. A product that does not have its own website might be offered for sale by a third party on Amazon Marketplace, or used versions might be available on eBay, or customers might have blogged about the product. And in the unlikely case that a mark is used in commerce but has no online presence, a court should consider that when weighing the Google evidence.

To be sure, as described above, Google is not-and could not be-a completely automated process: human employees are responsible for many changes to Google's search algorithm, sometimes multiple times per day. This frequent adjustment has led to concerns about search-engine bias, including the concern that Google may be privileging its own content (such as from YouTube and Zagat) over third-party websites. ${ }^{82}$ Google argues that it is immune from antitrust liability for any search ranking manipulation because search results are protected speech under the First Amendment, ${ }^{83}$ an issue that is the subject of heated academic debate. ${ }^{84}$ But whether or not Google should be subject to antitrust liability, scholars such as Professor James Grimmelmann and Professor Eric Goldman have convincingly argued that calls for "search neutrality" regulation are incoherent due to the inherently subjective nature of search results. ${ }^{85}$

82. See Eric Goldman, Revisiting Search Engine Bias, 38 WM. Mitchell L. REV. 96, 104-05 (2011).

83. See Eugene Volokh \& DOnald M. FAlK, First AmEndment Protection For SEARCh ENGINE SEARCH RESUltS (Apr. 20, 2012), available at http://www.volokh.com/wp-content /uploads/2012/05/SearchEngineFirstAmendment.pdf.

84. See, e.g., Oren Bracha \& Frank Pasquale, Federal Search Commission? Access, Fairness, and Accountability in the Law of Search, 93 CORNELL L. REV. 1149 (2008); James Grimmelmann, Speech Engines, 98 MinN. L. REV. 868 (2014); Christopher S. Yoo, Free Speech and the Myth of the Internet as an Unintermediated Experience, 78 GEO. WASH. L. REV. 697 (2010).

85. Eric Goldman, Search Engine Bias and the Demise of Search Engine Utopianism, 8 YALE J.L. \& TECH. 188, 189 (2006) ("Search engine bias sounds scary, but this Essay explains why such bias is both necessary and desirable."); James Grimmelmann, Some Skepticism About Search Neutrality, in THE NeXT Digital DeCADE: EsSAys ON THE Future OF THE INTERNET 435, 456, 459 (Berin Szoka \& Adam Marcus eds., 2010) (arguing that search neutrality is "incoherent" and could "prevent search engines from helping users find the websites they want"); Goldman, supra note 82, at 107 (arguing that "search neutrality" is a mythical concept because "[e]very search engine design choice necessarily and unavoidably reflects normative values"); see also Geoffrey A. Manne \& Joshua D. Wright, If Search Neutrality Is the Answer, What's the Question?, 2012 COLUM. BUS. L. REV. 151, 
The inherent subjectivity of search does not mean that Google has the same problem as judges who rely on subjective hunches in evaluating trademarks. Search is subjective because different people search for different things using the same terms. Yet trademark law is supposed to be subjective in the sense of being based on personal opinions; it is just that the relevant opinion is that of the average consumer (which Google attempts to capture), not that of the average judge. This is not to say that Google is perfect-it is simply better than what courts do now.

To the extent that Google is intentionally skewing search results toward Google products, in most cases this would not affect the use of Google to study trademarks. ${ }^{86}$ For example, the first ten hits for [ SALLY'S pizza ] all referred to Sally's Apizza in New Haven, whether the search location was set to "United States," "Los Angeles," or "Cheyenne, Wyoming." locations, the first result was the Google+/Zagat review page for Sally's, followed by Yelp, Wikipedia, and TripAdvisor. The prominence of Google+ may be related to Google favoring its own content, but the search ranking of Google+ versus Yelp is irrelevant to evaluating the strength of the SALLY'S mark for pizza because both sites are using SALLY'S in the same manner (to refer to the New Haven pizza restaurant). ${ }^{88}$ The Google results provide compelling evidence that in the context of pizza, consumers primarily associate SALLY'S with the restaurant in New Haven (and not, for example, Sally's Classic Pizza in Worland, Wyoming ${ }^{89}$ ); in other words, Google shows that the New Haven SALLY'S has a strong mark for pizza. ${ }^{90}$

Relying on Google results in trademark law requires some acceptance of what Clay Shirky has termed Google's "algorithmic authority," or "the decision to regard as authoritative an unmanaged process of extracting value from

152 (" $[\mathrm{N}]$ either an ex ante regulatory restriction on search engine bias nor the imposition of an antitrust 'duty to deal' upon Google would benefit consumers.")

86. Courts could also correct for any bias in Google's searches by comparing its results to those of other search engines.

87. Searches were performed on January 13, 2013. Lest one think these results were influenced by my physical location in New Haven, friends in Seattle and in Grand Junction, Colorado, performed the same searches and obtained identical results.

88. Of course, if the trademark at issue were YELP and the Google results for [ YELP ] included an organic result for Google+ (which is not currently the case), courts should be wary of this evidence.

89. Sally's Classic Pizza is the first result if the search location is Worland, Wyoming, although the next nine hits are for Sally's Apizza in New Haven. But note that all of the top hits are for Sally's Apizza if the search location is Cheyenne, Wyoming.

90. A Bing search (on January 13, 2013) for [ SALLY'S pizza ] also provides evidence that SALLY'S is a strong mark for pizza: whether the search location is Los Angeles or Cheyenne, eight of the top ten results relate to Sally's Apizza in New Haven (the other two are for Sally's Classic Pizza in Worland, Wyoming, and a book called Pizza at Sally's that is unrelated to the New Haven restaurant). Unsurprisingly, Bing has a result for Bing Local rather than Google+; more interestingly, two of the top Bing results are for pages related to Sally's Apizza at www.pizzatherapy.com, which does not appear in the first hundred Google results. But for purposes of evidence in trademark cases, the ordering of different sites that use the trademark in the same way is irrelevant. 
diverse, untrustworthy sources, without any human standing beside the result saying "Trust this because you trust me." 91 The increasing reliance on algorithmic authority, as opposed to expert authority, might be troubling when the issue being addressed depends on expert wisdom. But for trademark purposes, it is irrelevant if the top Google results contain content errors or are otherwise untrustworthy - all that matters is that they are the results consumers are generally looking for. If one of the top Google results for [ CANON ] were a Nikon-sponsored site with false information about why Nikon cameras are better than Canon cameras, the false or biased nature of the content would be irrelevant for evaluating the strength of the CANON mark; the only relevant fact would be that this hypothetical site uses CANON as a source designator for the camera company, which is evidence of the strength of CANON as a mark. ${ }^{92}$

To be sure, Google results might also be erroneous in the more important sense of not being what the average searcher is looking for. If the most common association with SALLY'S in the pizza context is not the New Haven restaurant, or if the most common association with CANON is not the camera company, then the Google results in these cases would be erroneous in the same way that an unrepresentative survey sample might not accurately reflect consumer perceptions. Google results might sometimes be skewed by "Google bombing" or search-engine optimization, although I explain in Part III.0 why these techniques are unlikely to affect the usefulness of Google results for trademark disputes. In general, Google does provide the most relevant results to consumers, as indicated by its dominant market position and its practice of adjusting its algorithm to increase the frequency with which searchers click on, and stay on, the top results. And the fact that Google and the courts agree in the majority of cases discussed in Part II provides reassurance that Google results can in fact be useful. ${ }^{93}$

\section{Judicial Justifications for Ignoring Search Results}

Despite the potentially high probative value of search-engine evidence in trademark disputes, courts have thus far not been very receptive to this

91. Clay Shirky, A Speculative Post on the Idea of Algorithmic Authority, ClAY SHIRKY (Nov. 15, 2009, 4:06 PM), http://www.shirky.com/weblog/2009/11/a-speculative-post-on-the-idea-of -algorithmic-authority. Shirky notes that this model of authority "takes in material from multiple sources, which sources themselves are not universally vetted for their trustworthiness, and it combines those sources in a way that doesn't rely on any human manager to sign off on the results before they are published." Id.

92. As Eric Goldman has explained, this referential use of "Canon" should not constitute trademark infringement, though Canon might have an action for false advertising. See supra note 79. But whether this use of "Canon" creates legal liability is orthogonal to whether the search rankings are probative of CANON's strength as a mark.

93. These cases are not used as a baseline against which to measure Google because of the flaws in current methods of evaluating trademarks, but unless one thinks that courts err in the majority of cases, the general agreement between the methods should increase one's confidence in using Google results as evidence in trademark disputes. 
evidence. ${ }^{94}$ According to McCarthy on Trademarks, "Internet evidence is generally admissible and can be considered for the purpose of evaluating a trademark," but "[s]earch engine results which provide little context to determine how a term is actually used on the Web page listed on the result [are] generally not sufficient to determine the nature of use of a term by the public." ${ }^{95}$ For example, the Federal Circuit has stated that Google search results are "of lesser probative value than evidence that provides the context within which a term is used." 96 The court noted that search results "may be insufficient to determine the nature of the use of a term" and agreed with a TTAB decision "stating that [a] list of internet search results is "not given much weight.",97 Similarly, the Tenth Circuit concluded that "the number of search engine 'hits' [for a mark] would support [plaintiff's] claim of secondary meaning only if accompanied by some kind of evidence that the relevant market of consumers has visited the websites containing these hits." 98

District courts have been similarly dismissive of search-engine results. One court rejected an accused infringer's Google evidence of other uses of the asserted mark because "it is not readily apparent from the results whether the establishments are currently doing business" and the party "has not shown that establishments listed as using the mark had to pay Google to be listed or perform some other affirmative act that signifies the establishments are using the mark ... in commerce." 99 The court distinguished the Google results from listings in telephone directories, which require an affirmative act and are thus "some evidence of use." ${ }^{100}$ Another court rejected search evidence intended to show that MIX IT UP was merely descriptive for frozen beverages because the results did not demonstrate "third-party use on similar goods and services.",101

94. For a descriptive summary of some trademark cases where search-engine results were presented as evidence, most of which are not the kinds of typical trademark infringement cases discussed in this Article, see David M. Kelly \& Jaclyn N. Kidwell, Searching for Evidence in Trademark Cases?, 72 PAT. TRADEMARK \& COPYRIGHT J. 251 (2006).

95. 3 MCCARTHY, supra note $1, \S 20: 126.50$, at 20-282, 20-283. For more on the admissibility of search-engine results, see TeLisa T. Owens, Investigative Research on the Internet, MICH. B.J. 52 (2008), noting that "trial and appellate courts are now sua sponte performing Internet investigative research" and that "[c]ountless court opinions acknowledge the admission of Internetbased research."

96. In re Bayer Aktiengesellschaft, 488 F.3d 960, 967 (Fed. Cir. 2007).

97. Id. (quoting In re King Koil Licensing Co., 79 U.S.P.Q.2d (BNA) 1048 (T.T.A.B. 2006)).

98. Utah Lighthouse Ministry v. Found. for Apologetic Info. \& Research, 527 F.3d 1045, 1051 (10th Cir. 2008).

99. Lucky's Detroit, LLC v. Double L Inc., No. 09-14622, 2012 WL 219418, at *7 (E.D. Mich. Jan. 25, 2012)

100. Id.

101. Cook v. J \& J Snack Foods Corp., No. 2:09-CV-02297, 2010 WL 3910478, at *6 n.5 (E.D. Cal. Jan. 28, 2010). The evidence consisted of "the first page of the search results produced when the terms 'Mix It Up' and 'Mix It Up Frozen Beverage' are entered into the Google search engine." Id. 
In other cases, courts have rejected Google search evidence without explanation. ${ }^{102}$

These judicial discussions of search-engine evidence illustrate that the courts fail to appreciate why this evidence is probative. If search results were merely a list of websites using a mark, then the concerns raised by these courts would be relevant: additional evidence would be necessary to show that those websites were maintained by active businesses and were regularly visited by consumers. But the value of Google results is the ranking of sites based on relevance to the search terms. Websites do not need to perform an "affirmative act" to be listed, but a site will only appear on the first page of Google results if it is linked to by other sites using relevant keywords. ${ }^{103}$ Search results are thus stronger evidence of trademark use than telephone directory listings.

Not all courts have dismissed search-engine results. In a few cases, courts conducted their own online searches but seemed confused about how to use the results. ${ }^{104}$ One example of such confusion is focusing only on the relative rankings of the parties' websites, rather than on how a mark is used on a given site. When AR Pillow complained about the use of its AR PILLOW mark on the defendant's website (in a discussion of why the defendant's baby pillows were superior to the AR Pillow), the court suggested that it would be probative of confusion if the defendant's website showed up in a search for [ AR PILLOW ]. ${ }^{105}$ But the defendant used AR PILLOW to refer to the plaintiff as

102. See, e.g., Dahl v. Swift Distribution, Inc., No. CV 10-00551, 2010 WL 1458957, at *9 (C.D. Cal. Apr. 1, 2010) (rejecting evidence showing that when conducting a search for defendant's mark on Google, users are asked if they intended to search for plaintiff's mark); Sanofi-Aventis v. Advancis Pharm. Corp., 453 F. Supp. 2d 834, 851 n.8 (D. Del. 2006) ("The court does not believe that the Google results, which at times, directed the user to the other party's site, are probative of actual confusion.").

103. If a search term only appears on a handful of websites, those will be listed on the first (and only) page of search results as long as they have been indexed, but in those (extremely rare) cases the small number of search results is indicative of the distinctiveness of the search terms.

104. See First Franklin Fin. Corp. v. Franklin First Fin., Ltd., 356 F. Supp. 2d 1048, 1052 (N.D. Cal. 2005) (reporting that plaintiff's FIRST FRANKLIN mark appeared as a sponsored link and as the fourth hit in a search for defendant's FRANKLIN FIRST mark, and concluding that this showed that the marks were dissimilar); Best Vacuum, Inc. v. Ian Design, Inc., No. 04 C 2249, 2005 WL 1185817 , at $* 7 \&$ n. 4 (N.D. Ill. Jan. 18, 2005) (reporting the total number of search results (e.g., three million at Google) as evidence of a mark's common use and also stating that "the Court does not consider the rankings to necessarily be substantial evidence of a party's established place in the market”); Strange Music, Inc. v. Strange Music, Inc., 326 F. Supp. 2d 481, 492 (S.D.N.Y. 2004) (concluding that there would be no confusion between STRANGEMUSIC (at strangemusic.com) and STRANGE MUSIC (at strangemusicinc.com) because "[u]pon the Court's own search, Google and Yahoo! report over 50,000 sites employing the words 'strange music," and "[a] consumer looking for [plaintiff's] music [at strangemusic.com] would presumably link into one of the thousands of sites located by the search engine").

105. AR Pillow Inc. v. Cottrell, No. C11-1962 RAJ, 2012 WL 868109, at *2 (W.D. Wash. Mar. 13, 2012) (stating that because "there is no evidence in the record that use of the term AR Pillow in Google or other search engine currently leads to defendant's website" the similarity-of-the-marks factor "weighs in favor of defendant"); $i d$. at *4 ("Consumers who search for AR Pillow today are not presented with defendant's website in the rankings ...."). 
a source, not to refer to a different source - this is not "use" of the plaintiff"s mark, or at most is nominative use. ${ }^{106}$ For purposes of evaluating the strength of AR PILLOW, the plaintiff's website, the defendant's negative discussion of plaintiff's product, and third-party websites selling or discussing plaintiff's product are all equivalent.

In another case, the plaintiff alleged that searching for her BITCHEN KITCHEN mark brought up sites for defendant's BITCHIN' KITCHEN. ${ }^{107}$ Her argument was focused on the harm caused by this downgrade in search rankings, and the court conducted its own search-engine research to determine whether the plaintiff's site still showed up in the search results. ${ }^{108}$ As commentators have explained, this is the wrong inquiry: trademark infringement should not be based on whether the plaintiff's search rankings were downgraded, especially given the variations in results returned by different search engines and different searchers in this case. ${ }^{109}$ But the court may have gone too far in concluding that it "accords little weight to the plaintiffs' evidence ... regarding search-engine rankings," 110 as the court itself relied on search-engine evidence when assessing the similarity of the marks. The court noted that the marks "are so close to textually identical ... that when one searches for one of the terms with an internet search engine, each search engine used asks something to the effect of 'Did you mean [the other term]?' and/or states 'We have included results for [the other term].","111 These results illustrate Google's potential value for assessing the relative distinctiveness of the marks at issue.

Finally, in one case the court used Google to assess trademark strength in the manner discussed here-it conducted its own Google search to illustrate that 24 HOUR FITNESS was merely descriptive with weak evidence of secondary meaning (and not likely to be confused with 24/7 FITNESS for preliminary injunction purposes):

The Court's August 5, 2003 search through the www.google.com engine for the terms " 24 " "Hour" and "Fitness" produced a list of over one million hits, of which Plaintiff's site was the second. The results

106. See Eric Goldman, Trademark Lawsuit over Website Text Comparing Products Baffles the Judge-AR Pillow v. Cottrell, TeCH. \& MARKeting L. Blog (Mar. 21, 2012, 10:00 AM), http://blog.ericgoldman.org/archives/2012/03/trademark_lawsu_1.htm.

107. Martha Elizabeth, Inc. v. Scripps Networks Interactive, LLC, No. 1:10-CV-1244, 2011 WL 1750711, at*6 (W.D. Mich. May 9, 2011).

108. Id. at $* 6-7$ \& n. 7 .

109. See Eric Goldman, Quityerbitchin: Relative Search Results Placement Doesn't Support Trademark Injunction -Bitchen Kitchen v. Bitchin' Kitchen, TECH. \& MARKETING L. BLOG (May 15, 2011, 10:27 AM), http://blog.ericgoldman.org/archives/2011/05/quityerbitchin.htm; Rebecca Tushnet, Bitchfest: Court Worsens Parks While Refusing To Enjoin TV Show, REBECCA TUSHNET's 43(B)LOG (May 12, 2011，11:48 AM), http://tushnet.blogspot.com/2011/05/bitchfest-court-worsens-parkswhile.html.

110. Martha Elizabeth, 2011 WL 1750711, at*7.

111. Id. at $* 15$ 
include links to ... a discussion board of bodybuilding experts and "fitness babes" as well as a www.24hourteamsports.com site offering high school programs. ...

This simple exercise, with the application of simple logic, makes it apparent that any confusion or misdirection of a person using a general internet search engine to find Plaintiff's site would arise principally from the fact that Plaintiff has chosen to construct its mark out of common descriptive terms rather than inherently distinctive terms. The risk of confusion on this account is not as to Plaintiff's identity as the particular source of anyone's health club or fitness product. ${ }^{112}$

As the court concluded, the fact that only one of the top hits for [ 24 HOUR FITNESS ] seemed to refer to plaintiff's fitness centers suggested this was a weak mark. ${ }^{13}$ After four years of litigation (and the corresponding attorney fees), the Second Circuit affirmed a judgment of noninfringement. ${ }^{114}$ Increasing reliance on Google and other search results may help parties avoid these protracted disputes.

II.

GOOGLING TRADEMARKS: EMPIRICAL RESULTS

\section{A. Methodology}

New U.S. federal court decisions related to trademark or service mark distinctiveness or likelihood of confusion were tracked from December 2011 to November 2012. ${ }^{115}$ Cases were screened to select trademark infringement or registration disputes between unrelated companies over word marks (or design marks whose primary element was a searchable word), rather than licensing or ownership disputes over a single mark, trademark counterfeiting cases, cases involving gripe sites, or disputes primarily involving trade dress or design. ${ }^{116}$

112. 24 Hour Fitness USA, Inc. v. 24/7 Tribeca Fitness, LLC, 277 F. Supp. 2d 356, 366 (S.D.N.Y. 2003).

113. The 24 HOUR FITNESS mark seems to have gained commercial strength over the past decade, as it was related to all of the results on the first page of a Google search performed on November 26, 2012. 2007).

114. 24 Hour Fitness USA, Inc. v. 24/7 Tribeca Fitness, LLC, 247 F. App’x 232 (2d Cir.

115. A daily alert for Westlaw's ALLFEDS database was set up with this search query: [ (TRADEMARK "SERVICE MARK") \& (( (TRADEMARK MARK) /S (DISTINCTIVE! STRENGTH)) (DESCRIPTIVE /S SUGgESTIVE) (LIKEL! /S CONFUS!)) ]. The earliest case in the dataset is from December 6, 2011; the latest is from November 15, 2012.

116. These cases were selected because they are the ones in which search-engine results are most useful. Google is a poor tool for determining the proper owner of a mark. In cases involving commentary on a mark, such as on gripe sites, the defendant is using the mark to refer to the original source, so under my methodology, these would never be confusing uses. Cf. supra note 79 (explaining why such use should not constitute trademark infringement). And as previously noted, Google search is currently unable to provide evidence of the distinctiveness of design marks or trade dress. See supra note 13 . 
The dataset includes preliminary injunction orders and other decisions in which the court made some assessment of the merits, not just final decisions. ${ }^{117}$ The resulting dataset contains eighty-eight cases.

Google searches were performed for the relevant trademarks in each case, both alone and with multiple keywords describing their field of use as alleged by the party asserting the mark. For example, when Kimono condoms asserted that its MICROTHIN mark was being infringed by the use of MICRO-THIN for Trojan condoms, ${ }^{118}$ searches were performed for [ MICROTHIN ], [ MICRO-THIN ], [ MICROTHIN condoms ], and [ MICRO-THIN condoms ]. ${ }^{119}$ The location for each search was set as the city of the district judge who heard the case. ${ }^{120}$ In actual disputes, one should perform searches for a variety of relevant locations, as well as with the search location set to "United States" to minimize local effects, although these do not seem significant in most cases. ${ }^{121}$ To avoid other personalized search effects, ${ }^{122}$ searches were performed in "incognito mode" in the Chrome web browser. ${ }^{123}$ Searches were generally performed within a week of the decision date. ${ }^{124}$

117. Note that federal trademark cases might be tried to either a jury or a court. See Dairy Queen, Inc. v. Wood, 369 U.S. 469, 479 (1962) (holding that the Seventh Amendment right to a jury applies to trademark actions for damages); Mark A. Thurmon, Ending the Seventh Amendment Confusion: A Critical Analysis of the Right to a Jury Trial in Trademark Cases, 11 TeX. INTELL. PROP. L.J. 1 (2002).

118. Church \& Dwight Co. v. Mayer Labs., Inc., 868 F. Supp. 2d 876 (N.D. Cal. 2012), vacated in part, 2012 WL 1745592 (N.D. Cal. May 16, 2012).

119. The exact search terms are obviously somewhat subjective, but I erred on the side of performing more searches. For multi-word marks, I typically performed searches both with and without quotation marks around the mark. If all of the top results relate to the mark without quotation marks (such as for [ PAY LESS shoes ]), then they also all relate in the more restrictive search with quotation marks (such as [ "PAY LESS" shoes ]), and I do not report these results. Similarly, if none of the top results relate to the mark with quotation marks, then none of the top results relate when the quotation marks are removed.

120. For information about Google search locations, see Change Your Location on Google, GOOGLE, http://support.google.com/websearch/bin/answer.py?hl=en\&answer=179386 (last visited Jan. 2, 2014). Searches for cases from Puerto Rico were performed at the Puerto Rican Google site, Google.pr (using English and Spanish words to describe the field of use); in some cases, these results were compared to those at Google.com with the location set to "Miami," and they were very similar.

121. See infra notes $274-76$ and accompanying text.

122. For further discussion of personalization, see infra notes 268-71 and accompanying text.

123. See Incognito Mode (Browse in Private), GooGLE, http://support.google.com/chrome/bin /answer.py?hl=en\&answer=95464 (last visited Jan. 2, 2014).

124. Searches were generally performed within a few days of receiving the Westlaw alert, which is typically within a few days of the decision date. As of November 4, 2012, the median time between decision date and search date was 5 days, and the mean was 6.7 days. Delays were due to decisions that took longer to appear in the Westlaw alert; the longest delay was for Wecosign, Inc. $v$. IFG Holdings, Inc., 845 F. Supp. 2d 1072 (C.D. Cal. 2012), which was decided on January 23, 2012, but did not show up in the Westlaw alert until 38 days later, on March 1, 2012 (when the Google search was performed). In a few cases, an additional search with different keywords was performed several months after the case was decided, but only after confirming that the original searches for that case gave roughly equivalent results. 
For each search, the first page of results - which generally contains ten hits - was examined; these results are referred to as the "top results" or "top hits" throughout this Part. ${ }^{125}$ This study focuses only on the first page of results because very few users examine the subsequent pages. ${ }^{126}$ For ease of analysis, no distinction was drawn between search positions on the first page of results, so that a mark that was related to the first hit is treated the same as a mark related to hit number ten. Consumers are far more likely to click on the first few search results than the last few, ${ }^{127}$ so the first few search positions should be weighted more heavily (and courts should be aware of this if there are close cases where result order matters). But I found that merely being related to the first search result is insufficient to establish trademark validity, and it is highly unlikely in practice that a mark would be related to enough results to be protectable without having any of the top search positions.

Parts III.0 and III.0 explain how these search results were analyzed to assess trademark distinctiveness and the similarity of the marks. To test the robustness of this method, on January 20, 2013 (after circulating an initial draft of this Article), I ran every search described in this Article again, using both the original search location and a broader "United States" search. As described in Part III.0, in only two cases did these new search results affect the outcome of either prong of the trademark analysis. ${ }^{128}$

\section{B. Trademark Distinctiveness}

As explained in the Introduction, distinctiveness is central to the threshold question of a mark's validity as a binary yes-no question, and the degree of distinctiveness is also critical for determining a mark's strength (and thus its scope of protection). ${ }^{129}$ Doctrinally, distinctiveness can be either inherent based on linguistic uniqueness, or acquired based on consumer recognition, and trademark strength is assessed by weighing these factors in a two-pronged

125. In addition to ten websites, the first page of search results also sometimes contains other Google results, such as from Google Places (which was replaced by Google+ Local and Zagat in May 2012), Google Images, or Google News, which were not included in this study for consistency across searches. Because video results did count as one of the ten hits displayed on the first page, these were included in the study. In some cases, Google displays three rows of indented links under the first hit, which together count as four of the ten hits on the first page - for example, my search for [ USAIRWAYS ] on November 23, 2012 had www.usairways.com as the first hit, with one indented row starting with "Flight status," one with "Book travel," and one with "Dividend Miles," and this block (which counts as four) is followed by a Google News item (which does not count) and then six additional hits (making ten hits on the first page).

126. See Rick Dejarnette, Click-Through Rate of the Top 10 Search Results in Google, INTERNET MARKETING NINJAS BLOG (Jan. 24, 2012), http://www.internetmarketingninjas.com/blog /search-engine-optimization/click-through-rate. In future research, it would be interesting to see whether incorporating later pages, or weighting results within the first page, has any significant effect on the results.

127. See id.

128. See infra notes $274-76$ and accompanying text.

129. See supra notes 1-4 and accompanying text. 
[Vol. 102:351

test. ${ }^{130}$ In assessing trademark strength through Google, these two prongs are collapsed into a single distinctiveness test: if a mark is either inherently distinctive or commercially strong, then the top Google hits should relate to that mark.

To assess the distinctiveness of each mark at issue in my cases, I determined how many of the top ten results related to the source identified by the asserted mark. For example, the first page for [ MICROTHIN ] had three hits related to Kimono MicroThin condoms, two related to mouse pads by Microthin.com, four related to a "micro thin" computer monitor by HewlettPackard, and an Amazon page with various "micro thin" screen protectors. Once the search was limited to [ MICROTHIN condoms ] or [ MICROTHIN condoms ], however, all ten hits on the first page of Google results related to Kimono condoms. ${ }^{131}$ This suggests that MICROTHIN is a strong mark for condoms, and also that its scope of protection should be limited to condoms. (It might also mean that MICROTHIN is a generic term in a singleplayer market, ${ }^{132}$ although there are many similarly thin condoms on the market that use different descriptors. ${ }^{133}$ ) The district court initially concluded to the contrary that MICROTHIN was not a valid mark, finding that " microthin' is descriptive because it immediately conveys the intended meaning as to the type of condom sold - one that is extremely thin," and that it lacked secondary meaning. ${ }^{134}$ On reconsideration, however, the court concluded that there was a genuine issue of material fact on secondary meaning, and it vacated its grant of summary judgment for Trojan. ${ }^{135}$ The Google results suggest that the court was right to revise its decision: when consumers search for MICROTHIN condoms, they are not simply looking for condoms that are "extremely thin"- they are generally looking for Kimono MicroThin condoms.

130. See 2 MCCARTHY, supra note $1, \S 11: 83$.

131. A sponsored link related to Trojan condoms, but as discussed earlier, I only considered organic search results.

132. See infra note 247 and accompanying text.

133. See, e.g., Sensitive Condoms, CONDOM DEPOT, http://www.condomdepot.com /product/catalog.cfm?nid=205 (last visited Jan. 13, 2013) (selling "extra sensitive" condoms with descriptions such as "Skinless," "Bare," "Extra Sensitive," "Ultra Sensitive," "Ultra Thin," "Bare Skin," and "Extra Thin"); Thinner Condoms, UnDERCOVER CONDOMS, http://www.undercover condoms.com/Condoms/Types/Thinner/13/thin-condoms.html?DivID=CondomStyles (last visited Jan. 13, 2013) (selling "Ultra Thin" or "Ultra-Thin" condoms from six different manufacturers). There may be many generic designations for a single product, see 2 MCCARTHY, supra note $1, \S 12: 9$, and a court might still decide as a matter of law that Kimono should not be allowed to exclude other manufacturers from using the term "microthin." Cf. Lisa P. Ramsey, Descriptive Trademarks and the First Amendment, 70 TENN. L. REV. 1095, 1169 (2003) (arguing that all descriptive marks should be eliminated from trademark protection). But the court should make this judgment with knowledge that the most relevant search results for "microthin" all currently relate to Kimono.

134. Church \& Dwight Co. v. Mayer Labs., Inc., 868 F. Supp. 2d 876, 925 (N.D. Cal. 2012).

135. Church \& Dwight Co. v. Mayer Labs., Inc., No. C-10-4429, 2012 WL 1745592, at *1-2 (N.D. Cal. May 16, 2012). 
In other cases, the Google results indicated a more tenuous connection between the asserted mark and the corresponding product. For example, Unleashed Doggie Day Care in Massachusetts asserted rights to the mark UNLEASHED for dog care (grooming, boarding, walking, and pet supplies), and it claimed that the pet supply store Unleashed by Petco infringed this mark. ${ }^{136}$ But Unleashed Doggie Day Care was only related to one of the top ten Google results for [ UNLEASHED dogs ], and it was not related to any of the top results for [ UNLEASHED ], [ UNLEASHED dog grooming ], [ UNLEASHED dog boarding ], [ UNLEASHED dog walking ], or [ UNLEASHED pet supplies ]. ${ }^{137}$ In other words, when consumers search for UNLEASHED, they are generally not looking for Unleashed Doggie Day Care - consumers do not view UNLEASHED as identifying this source. This suggests that the court was correct in determining that UNLEASHED as used by Unleashed Doggie Day Care was ineligible for trademark protection as a descriptive mark without secondary meaning. ${ }^{138}$

In most of the cases studied, there was a similar correlation between the court's assessment of the strength of the asserted mark and the number of hits for the corresponding product in the first page of Google search results for the mark. When the court found a mark to be unprotectable, there were few hits: MOM SONG was found to be generic, ${ }^{139}$ and none of the top ten hits for [ MOM SONG ] or [ "MOM SONG" ] were related to the plaintiff's song. ${ }^{140}$ A plaintiff asserting the mark ALL METAL moved for judgment as a matter of law after an adverse jury verdict, and the court found the evidence insufficient to establish secondary meaning and likelihood of confusion ${ }^{141}$ and only one of the top hits for [ "ALL METAL" ] related to the plaintiff's All Metal Sales, Inc.

When the court found a mark to be protectable but not strong, the corresponding product was typically more prevalent in the Google results. For example, WEST COAST CORVETTES was found to be "likely suggestive" in

136. Unleashed Doggie Day Care, LLC v. Petco Animal Supplies Stores, Inc., No. 10-10742DJC, 2011 WL 6812642 (D. Mass. Dec. 28, 2011).

137. These search terms were based on the asserted rights; the abandoned trademark application sought "to register the mark 'Unleashed' for the categories of 'Dog Grooming and Boarding Services and supplies and Retail store services in the field of animal and pet supplies." Id. at *2.

138. See id. at $* 8$.

139. Coble v. Renfroe, No. C11-0498, 2012 WL 503860, at *5 (W.D. Wash. Feb. 15, 2012).

140. The title of a single literary work (such as a song or video game title) cannot be registered as a trademark with the PTO, but it will be protected as an unregistered trademark if it has acquired secondary meaning. 2 MCCARTHY, supra note $1, \S 10: 4$. "The test of secondary meaning for literary titles is essentially one of determining whether, in the minds of a significant number of people, the title in question is associated with a single source of the literary work." Id. § 10:10, at 10-30.

141. All Metal Sales, Inc. v. All Metal Source, LLC, No. 1:10 CV 2343, 2012 WL 1831235, at *3 (N.D. Ohio May 18, 2012). 
a preliminary injunction order, ${ }^{142}$ and the corresponding paint and body shop was related to six of the top hits for [WEST COAST CORVETTES ]. SMART CHICKEN was found to be "at least suggestive" for chicken, ${ }^{143}$ and five hits for [ SMART CHICKEN ] related to that brand of chicken. HEALTHONE was found to be "strong commercially, but . . . weak conceptually" (so that the strength of the mark is "neutral"), ${ }^{144}$ and four of the hits for [ HEALTHONE ] related to the Denver hospital system asserting the mark. KINBOX was found to be weak conceptually and commercially for a Facebook application, ${ }^{145}$ and only three hits for [ KINBOX ] related to that application.

Finally, when the court determined that the mark was famous or strong, most of the top hits related to that product: SUZUKI ${ }^{146}$ and NEWPORT ${ }^{147}$ were found to be famous for vehicles and cigarettes, and all of the top hits for [ SUZUKI vehicles ] ${ }^{148}$ and [ NEWPORT cigarettes ] ${ }^{149}$ were related to those products. ROLEX was found to meet the higher standard of fame for dilution, ${ }^{150}$ and all of the top hits for [ ROLEX ] related to the watch company. POTENZA and TURANZA are "strong marks for tires" because they are "arbitrary" and the evidence "show[ed] commercial strength," those tires related to all of the top ten hits for [ POTENZA tires ] and [ TURANZA tires ]. Although WALTER MERCADO is a personal name, which courts generally consider to be descriptive, it "ha[d] acquired secondary meaning" because the "record ... [was] saturated with the psychic and astrological work produced and sold to the public under the name Walter Mercado," 152 and all of the top hits for [ WALTER MERCADO ] referred to Mercado's work as an astrologer. ${ }^{153}$ ORIENTAL was "strong in Puerto Rico"

142. W. Coast Corvettes, Inc. v. MV Mktg., Inc., No. SACV 12-0269, 2012 WL 1401433, at *7 (C.D. Cal. Apr. 23, 2012).

143. Tecumseh Poultry LLC v. Perdue Holdings, Inc., No. 4:12-CV-3032, 2012 WL 3018255, at $* 5$ (D. Neb. July 24,2012 ).

144. HealthONE of Denver, Inc. v. UnitedHealth Group Inc., 872 F. Supp. 2d 1154, 1180 (D. Colo. 2012)

145. Kinbook, LLC v. Microsoft Corp., 866 F. Supp. 2d 453, 466-67 (E.D. Pa. 2012).

146. Suzuki Motor Corp. v. Jiujiang Hison Motor Boat Mfg. Co., No. 1:12-CV-20626, 2012 WL 2873733, at*11 (S.D. Fla. June 29, 2012).

147. Lorillard Tobacco Co. v. Cal. Imps., LLC, 886 F. Supp. 2d 529, 535 (E.D. Va. 2012).

148. Eight of the top ten hits for [ SUZUKI ] related to the vehicle manufacturer; the other two were for the Suzuki method of learning music and a Nissan dealer (with no apparent connection to Suzuki).

149. Only one hit for [ NEWPORT ] was related to the cigarette manufacturer; the others were mostly related to the town of Newport, Rhode Island.

150. Rolex Watch U.S.A., Inc. v. Rolex Deli Corp., No. 11-CV-9321, 2012 WL 5177517, at *3 (S.D.N.Y. Oct. 18, 2012).

151. See Bridgestone Ams. Tire Operations, LLC v. Fed. Corp., 673 F.3d 1330, 1336 (Fed. Cir. 2012).

152. Mercado-Salinas v. Bart Enters. Int'1, Ltd., 852 F. Supp. 2d 208, 223 (D.P.R. 2012).

153. Courts should be cautious in using Google to assess whether a personal name has acquired secondary meaning. If all of the top search results for a name refer to the person asserting 
for banking and financial services, ${ }^{154}$ and ten hits for [ ORIENTAL bank ], eight for [ ORIENTAL banco ] (bank), and ten for [ ORIENTAL banca ] (financial services) were related to this bank. XEN was "strong" and had "prevalent use in commerce" for virtualization software, ${ }^{155}$ and eight of the top ten hits for [ XEN ] were related to that software.

A rough relationship between trademark strength and relevant hits in the top ten Google results is shown in Table $1 .{ }^{156}$ As discussed previously, I did not distinguish between different search positions on the first page of results, but these distinctions did not matter in practice. ${ }^{157}$ It is worth emphasizing that the keywords used in addition to the mark are important for determining what fields a mark is strong in: if all of the top hits for [ MARK field ] relate to a particular product but none of the top hits for [ MARK ] alone do, that suggests that MARK is a strong mark in that field but not outside it. Sixty-four out of the eighty-eight cases studied (73 percent) had trademark strength determinations that were consistent with this table. ${ }^{158}$ Part II.0 will discuss the cases where the courts and this Google test disagree for at least one of the marks at issue, but first Part II.0 discusses how Google results can be probative in a likelihood-of-confusion analysis.

TABLE 1: Relationship Between Trademark Strength and Hits Related to Product in the Top 10 Google Results

\begin{tabular}{|l|l|}
\hline \multicolumn{1}{|c|}{ Strength of the Mark } & \multicolumn{1}{c|}{ Hits in Top Ten Google Results } \\
\hline $\begin{array}{l}\text { Unprotectable (generic or descriptive with no } \\
\text { secondary meaning) }\end{array}$ & $0-2$ \\
\hline $\begin{array}{l}\text { Weak (suggestive, or descriptive with acquired } \\
\text { distinctiveness, but weak commercial strength) }\end{array}$ & $3-5$ \\
\hline $\begin{array}{l}\text { Medium (weak conceptually but strong } \\
\text { commercially, or strong conceptually and weak } \\
\text { commercially) }\end{array}$ & $4-8$ \\
\hline Strong (in that field) or famous & $8-10$ \\
\hline Famous for dilution & $\begin{array}{l}10 \text { for mark alone (no other keywords) } \\
\text { (necessary but not sufficient to show fame) }\end{array}$ \\
\hline
\end{tabular}

trademark rights in that name, that person may be the most well-known person with that name - but it does not necessarily mean that the public understands the name to signify the source of goods or services, as required for trademark rights in a name. See 2 MCCARTHY, supra note 1, § 13:4. In the case of Walter Mercado, I think it is significant that all of the search results refer to his work providing astrology services.

154. Oriental Fin. Grp., Inc. v. Cooperativa de Ahorro y Crédito Oriental, 698 F.3d 9, 18 (1st Cir. 2012).

155. Xen, Inc. v. Citrix Sys., Inc., No. CV-11-09568, 2012 WL 5289609, at *3 (C.D. Cal. Oct. $25,2012)$.

156. Note that while the numbers in this table captured most of the results in my dataset, the specific cutoffs may shift over time if Google weights its algorithm toward more or less diversity in results.

157. See supra note 127 and accompanying text.

158. This count includes cases where the mark was strong enough for protection but was not placed in a specific strength category, for which the number of hits corresponding to the associated product ranged from three to ten. 


\section{Likelihood of Confusion}

Google results may also have probative value in evaluating the likelihood of confusion between two marks beyond estimating the strength of the plaintiff's mark. As explained in the Introduction, each circuit evaluates confusion using its own multifactor test. ${ }^{159}$ Google results reveal nothing about some of these factors, such as the defendant's intent. ${ }^{160}$ But "by far the most important factor," according to Barton Beebe's empirical study, is the similarity of the marks. ${ }^{161}$ Google may help courts evaluate this factor: if some of the top Google results for one party's mark relate to the other party's product, this finding may indicate that the marks are less distinctive from each other and thus more likely to create confusion. ${ }^{162}$ And the inverse may also be true: if none of the top hits for each mark relate to the other product, confusion seems unlikely.

I am not claiming that the searchers themselves are (or are not) actually confused. As previously noted, a searcher's intent is difficult to interpret, and someone searching for a mark might be searching, for example, for comparisons with competitors. ${ }^{163}$ But such comparisons still count as using the mark to refer to its source; what Google rankings illustrate is whether the sites that are most relevant to the average searcher use the mark to refer to its source. ${ }^{164}$ If a search for one mark has some results for the other source alone (i.e., not as a comparison between the two sources), it likely means that a large number of searchers in fact want those results - but it also means that the marks are similar enough that their source-indicating signals are being mixed. This Section describes a number of cases from the dataset that illustrate this potential of using Google to evaluate the similarity of two marks (and therefore, to the extent similarity is the dominant factor, the likelihood of confusion).

When the maker of SPIDERWIRE fishing line sued the maker of SPIDER THREAD fishing line, the court held that SPIDERWIRE was "an arbitrary

159. See supra note 19 and accompanying text.

160. The defendant's intent or good faith in selecting a mark is an explicit factor everywhere except the Federal Circuit, where it may still be relevant. See 4 MCCARTHY, supra note 1, §§ 24:3143.

161. Beebe, supra note 7, at 1623.

162. In some cases, the only search overlap between the marks was related to the trademark lawsuit itself, which I did not take to be evidence of similarity and which illustrates the importance of performing Google searches early in a dispute.

163. See supra note 79 and accompanying text.

164. I have not found any examples where searching for one strong mark results in organic results for competitors' websites that do not mention the search term; for example, McDonalds.com is not a top hit for [ BURGER KING ] (though "mcdonalds" is suggested by Google as one of the "[s]earches related to burger king"). Thus, if some of the top results for the junior user's mark relate solely to the senior source (as opposed to comparing the sources), this likely means that a significant number of searchers think the junior mark signifies the senior source, and not that the average searcher is trying to compare competitors. 
mark that has attained conceptual strength" and that "the evidence shows a likelihood of confusion." 165 Plaintiff's fishing line related to all ten of the top hits for [ SPIDERWIRE ], showing that this is a strong mark. Further, plaintiff's fishing line related to nine hits for [ SPIDER fishing line ], showing that the common portion of the marks-SPIDER-is strongly associated with plaintiff's fishing line product. A search for [ SPIDER THREAD fishing line ] had just four hits for defendant's product and two hits for plaintiff's, suggesting that SPIDER THREAD is a relatively weak mark for fishing line and that consumers might associate this mark with plaintiff's SPIDERWIRE product. These findings do not mean that consumers who search for [ SPIDER THREAD fishing line ] are themselves confused - the results overlap simply indicates that the marks are more similar than if there were no overlap.

Similarly, when Korum Auto Group alleged that its KORUM mark was infringed by defendant's use of the name KORUM'S AUTO OUTLET, the court granted a preliminary injunction because KORUM was "protectable" as "associated with automobile dealerships," and because plaintiff was likely to prove likelihood of confusion. ${ }^{166}$ A search for [ KORUM ] had four hits for plaintiff and none for defendant; [ KORUM cars ] had five for plaintiff and two for defendant; and [ KORUM auto ] had three for plaintiff and seven for defendant. This case illustrates that Google cannot determine who is the senior user of a given mark, and perhaps that a Google-based strength assessment should be adjusted upward if most of the non-plaintiff-related hits are for the defendant. ${ }^{167}$ But in any case, these results (even without upward adjustment) suggest that KORUM is a valid mark for Korum Auto Group and that the marks are very similar, suggesting that the court was correct in granting a preliminary injunction.

Even a single overlap in the top Google hits provides some weak evidence of the similarity of the marks. The court found a likelihood of confusion between plaintiff's OTELS (for travel services at otels.com) and defendant's OTEL (for travel services at otel.com), ${ }^{168}$ and [ OTELS ] had five hits related to plaintiff's website and one related to defendant's. Similarly, there was a likelihood of confusion between BUMPER TO BUMPER (for auto parts

165. Pure Fishing, Inc. v. Redwing Tackle, Ltd., 888 F. Supp. 2d 726, 733 (D.S.C. 2012).

166. Korum Auto. Grp., Inc. v. Salstrom Motors Inc., No. CV-11-5690, 2012 WL 135414, at *3-4 (W.D. Wash. Jan. 17, 2012).

167. Ideally, the senior user would have Google search evidence from before the junior user's entry. See infra note 257 and accompanying text.

168. Otels, Inc. v. Altun, No. 1:11-CV-0604, 2012 WL 3522616, at*4-5 (E.D. Va. June 13, 2012) (finding a likelihood of confusion for a default judgment), report and recommendation adopted, 2012 WL 3522611 (E.D. Va. Aug. 14, 2012). 
[Vol. 102:351

and services) and BUMPER2BUMPER (for vehicle sales). ${ }^{169} \mathrm{~A}$ search for [ "BUMPER TO BUMPER" ] had five hits for plaintiff and one for defendant. There was also a likelihood of confusion between CARPET COPS (a carpet cleaning company in Nevada) and THE CARPET COPS (a carpet cleaning company in Utah), ${ }^{170}$ and [ "CARPET COPS" ] had five hits for plaintiff and one for defendant. Whether these infringement claims should actually succeed likely will depend on one's underlying theory of trademark law, but the Google results are useful for evaluating the relative distinctiveness of the marks to consumers.

Extensive results overlap does not mean a trademark infringement claim should succeed, however, if the asserted mark is not protectable. For example, when Rockland Exposition alleged that its NORTHEAST service mark for auto trade shows was infringed by the Alliance of Automotive Service Providers' use of NORTHEAST for auto trade shows, the court concluded that there was no "evidence from which a reasonable jury could find that [Rockland's] use of [the descriptive mark] 'Northeast' ha[d] acquired secondary meaning," and that there was thus no need to consider whether defendant's use would cause confusion. ${ }^{171}$ Of the top ten hits for [ NORTHEAST auto trade show ], there was one for plaintiff, five for defendant, and the rest for three other auto shows; the top hits for [ NORTHEAST auto show ] included zero for plaintiff, one for defendant, and the rest for four other auto shows. These results suggest that the court correctly found that Rockland does not have protectable rights in NORTHEAST. Because consumers do not strongly associate NORTHEAST with Rockland, its use by other trade shows is unlikely to cause confusion.

A number of cases in my dataset found no confusion even though the mark was protectable. For example, in a dispute between competitors in the foot-care products market, the court found no likelihood of confusion (at the preliminary injunction stage) between PROFOOT and Dr. Scholl's use of P.R.O. for its Pain Relief Orthotics line. ${ }^{172}$ The PROFOOT products were related to all ten top hits for [ $\mathrm{PROFOOT}$ ], five for [ $\mathrm{PRO} F O O T$ ], and nine for [ PRO FOOT CARE ] - none of the hits related to Dr. Scholl's P.R.O. line. The court noted that P.R.O. was always "located immediately next to the words "Pain Relief Orthotic" and on packaging that sold as a "sub-brand of [Defendant's] Dr. Scholl's 'house brand,"' so that the competing mark is not

169. Aftermarket Auto Parts Alliance, Inc. v. Bumper2Bumper, Inc., No. 1:12-CV-00258-NT, 2012 WL 4753407, at*1-4 (D. Me. Oct. 4, 2012) (finding a likelihood of confusion for a temporary restraining order).

170. Carpet Cops, Inc. v. Carpet Cops, LLC, No. 3:11-CV-00561, 2012 WL 3929783, at*3-5 (D. Nev. Sept. 6, 2012) (finding a likelihood of confusion for a default judgment).

171. Rockland Exposition, Inc. v. Alliance of Auto. Serv. Providers of N.J., 894 F. Supp. 2d 288, 324 (S.D.N.Y. 2012).

172. ProFoot, Inc. v. MSD Consumer Care, Inc., No. 11-7079, 2012 WL 2262904, at*11 (D.N.J. June 14, 2012). 
"P.R.O." in isolation. ${ }^{173}$ This is supported by the fact that Dr. Scholl's product does not show up for the above searches, but is related to eight of the top hits for [ PAIN RELIEF ORTHOTICS ]. The only results overlap was for [ SCHOLL'S PRO FOOT ], which had a few hits for general foot-care pages related to both products; for example, one hit was for a Drugstore.com page titled "Buy foot care, blisters \& bunions, and insoles online" with links to buy many different foot-care products, including Dr. Scholl's P.R.O. and ProFoot products.

In another case, the court found no likelihood of confusion (again at the preliminary injunction stage) between two sucker rods for crude oil production: FIBEROD and FINALROD. ${ }^{174}$ The court was willing to assume that plaintiff's FIBEROD was a "distinctive, strong mark." [ FIBEROD ] related to plaintiff's sucker rod product. But the court found no substantial likelihood that the plaintiff would demonstrate a likelihood of confusion due to the sophistication of sucker rod customers and the use of "rod" in the names of other sucker rods. ${ }^{176}$ The lack of any overlap in Google results supports this finding.

When Coach Services, which uses COACH for handbags and other luxury goods, challenged another company's registration of $\mathrm{COACH}$ for test preparation materials, the Federal Circuit found that the $\mathrm{COACH}$ mark for handbags was "famous for purposes of likelihood of confusion" but unlikely to cause confusion, and that it had failed to provide sufficient evidence of fame for purposes of dilution. ${ }^{177}$ The conclusion that $\mathrm{COACH}$ is not famous enough for dilution was surprising to some, ${ }^{178}$ but it seems correct under the Google test described above: [ $\mathrm{COACH}$ bags ] had ten hits for the handbag company, but [ $\mathrm{COACH}$ clothes ] had only six and [ $\mathrm{COACH}$ ] alone had only two (with other hits relating to sports coaches, the Coach television series, and transit services including Coach USA). Google also suggests that the court correctly found no likelihood of confusion: [ $\mathrm{COACH}$ testing ] had no hits for the handbag company.

As a final example, a court found no likelihood of confusion between SWATCH for watches, clocks, and related goods and SWAP for interchangeable watch faces and bands (which allow customers to "swap" one watch band for another). ${ }^{179}$ The court found plaintiff's SWATCH mark to be

173. Id. at *4.

174. John Crane Prod. Solutions, Inc. v. R2R \& D, LLC, 861 F. Supp. 2d 792, 801 (N.D. Tex. 2012).

175. Id. at 795

176. Id. at $798-800$.

177. Coach Servs., Inc. v. Triumph Learning LLC, 668 F.3d 1356, 1373 (Fed. Cir. 2012).

178. See, e.g., Charles Colman, Federal Circuit to Coach: Your Trademark Isn't "Famous" Enough for Federal Anti-Dilution Law (At Least, Not on This Record), LAW OF FASHION (Feb. 23, 2012), http://lawoffashion.com/blog/story/02/23/2012/118.

179. Swatch, S.A. v. Beehive Wholesale, L.L.C., 888 F. Supp. 2d 738, 756 (E.D. Va. 2012). 
conceptually and commercially strong, ${ }^{180}$ and all of the top hits for [ SWATCH ] related to plaintiff's watch company. Further, none of the hits for [ SWAP watch ] related to plaintiff, supporting the court's conclusion that the marks are not sufficiently similar to cause confusion.

\section{When Do the Courts and Google Disagree?}

So far, this Part has described a subset of the cases where the court's finding on trademark strength and likelihood of confusion was consistent with the Google search results for the relevant marks - a test that will be referred to as the "Google shortcut." But my claim is that Google does a better job than courts in evaluating the factual issue of consumer perceptions of trademarks, so the most interesting cases are those in which Google and the courts disagree. This Section describes all twenty-eight cases in which some aspect of the result was inconsistent with the Google shortcut. First are three cases in which Google suggests a likelihood of confusion between the marks, but this conclusion is "wrong" because such confusing concurrent use is in fact legally permissible under trademark law. Second are thirteen cases in which Google suggests that the court underestimated the trademark strength; in only three of these cases does Google suggest that the court may have erred in finding no likelihood of confusion. ${ }^{181}$ Third are ten cases in which Google suggests that the court overestimated trademark strength, eight of which also seem to mistakenly find a likelihood of confusion. Finally, there are only two cases in which the court and the Google shortcut agreed on the strength of the asserted mark (based on Table 1) but disagreed on likelihood of confusion. I will argue that in all but the first three cases described, Google search results provide evidence more convincing than the courts' contrary analysis.

\section{When Google Goes Wrong}

These first three cases illustrate the difficulty Google has when concurrent use of identical (or confusingly similar) trademarks is permissible under current trademark law. The Google results in these cases are not wrong in the sense of misrepresenting how consumers perceive the relevant marks; they are only wrong in that blindly applying the Google shortcut without considering the applicable law leads to the wrong legal result. These cases thus serve as a reminder that the expert authority of judges is still necessary to interpret Google's algorithmic authority.

The first two cases allow a geographically separate, good-faith junior user to maintain concurrent use with a senior user who relies on common law

180. Id. at $748-49$.

181. In this Section, I am assuming that the marks' relative distinctiveness - as indicated by whether or not searching for one mark gives results for the other source - is the dominant factor in the likelihood-of-confusion analysis. See supra notes 161-64 and accompanying text. 
rights. ${ }^{182}$ Both cases involve a senior common law mark that is strong in a small geographic area-HOTEL MELIÁ in Ponce, Puerto Rico, ${ }^{183}$ and HEALTHSOURCE CHIROPRACTIC in Rochester, New York ${ }^{184}$ Both involve a junior mark that is strong in a larger area-MELIÁ for one of the largest international hotel chains (including GRAN MELIÁ in Puerto Rico), and HEALTHSOURCE CHIROPRACTIC for a chain consisting of 325 franchisees in the United States (including HEALTHQUEST CHIROPRACTIC in Rochester). In both cases, the Google results for the senior mark are only strong when its city is included as a keyword, ${ }^{185}$ and searches for the senior mark result in hits for the stronger junior mark. In both cases, the court found factors favoring both parties but concluded that there was not a likelihood of confusion between the marks. ${ }^{186}$

Google, however, does not recognize geographically separated marks; setting a search location may weight local results more heavily, but a stronger national mark will still dominate. The Rochester chiropractor (the senior user of HEALTHSOURCE CHIROPRACTIC) even specifically noted this problem: "Plaintiff complains that a Google search for 'HealthSource Chiropractic' brings up HealthSource Inc.'s web site as the first result and Plaintiff's web site as the second." 187 The court concluded that "[a] trademark owner cannot reasonably expect to have exclusive use of a term on the internet." 188 Some scholars have argued that the realities of the Internet require rethinking the idea of geographically distinct markets. ${ }^{189}$ As long as trademark doctrine remains unchanged in this area, however, courts considering Google or other searchengine results in these kinds of cases (with a senior common law user and a

182. See 15 U.S.C. $\$ 1115(b)(5)$ (2012); 5 MCCARTHY, supra note 1, ch. 26 . Under the socalled Dawn Donut rule, "if the use of the marks by the registrant and the unauthorized user are confined to two sufficiently distinct and geographically separate markets, with no likelihood that the registrant will expand his use into defendant's market, so that no public confusion is possible, then the registrant is not entitled to enjoin the junior user's use of the mark." Dawn Donut Co. v. Hart's Food Stores, Inc., 267 F.2d 358, 364 (2d Cir. 1959).

183. Dorpan, S.L. v. Hotel Melia, Inc., 851 F. Supp. 2d 398, 410-11 (D.P.R. 2012). 2012).

184. Dudley v. Healthsource Chiropractic, Inc., 883 F. Supp. 2d 377, 389-91 (W.D.N.Y.

185. The hotel plaintiff is related to all ten hits for [ HOTEL MELIA Ponce ] but only one for [ HOTEL MELIA ], and the chiropractic plaintiff relates to seven hits for [ HEALTHSOURCE CHIROPRACTIC ROchester ] but only two for [ HEALTHSOURCE CHIROPRACTIC ].

186. Dudley, 883 F. Supp. 2d at 391-93; Dorpan, 851 F. Supp. 2d at 411.

187. Dudley, 883 F. Supp. 2d at 395.

188. Id.

189. See, e.g., Adam V. Burks \& Dirk D. Lasater, Comment, Location? Location? Location?: A New Solution to Concurrent Virtual Trademark Use, 11 WAKE FOREST J. BUS. \& INTELL. Prop. L. 329 (2011); Jessica Amber Drew, Death of Dawn Donut: The Demise of Concurrent Trademarks, 2007 U. ILL. J.L. TECH. \& POL'Y 145. I agree that the rise of online search limits the situations in which there can be "distinct and geographically separate markets" such that "no public confusion is possible." Dawn Donut Co. v. Hart's Food Stores, Inc., 267 F.2d 358, 364 (2d Cir. 1959); see supra note 182 (stating the Dawn Donut rule). 
geographically distinct good-faith junior user) should recognize this potential problem.

The third case is a family dispute in which BEERNTSEN CANDIES (founded in Green Bay, Wisconsin, in 1925) was found to be unprotectable against BEERNTSEN'S CONFECTIONARY (founded in Manitowoc, Wisconsin, in 1932, by the brother of the Green Bay confectioner). ${ }^{190}$ Seven of the top hits for [ BEERNTSEN CANDIES ] relate to the Green Bay store, and the court correctly noted that the store had "built up substantial goodwill" based on its "long history in the [candy] business." user of a descriptive mark cannot enforce its mark against a junior user without establishing secondary meaning before the junior user's first use, ${ }^{192}$ and there was no evidence showing that BEERNTSEN had acquired secondary meaning before 1932 (long before the development of online search engines). ${ }^{193}$ In such cases, where priority of use is important, courts should recognize that ex post search results can lead to the wrong legal result — and companies today might be advised to document Google search results before they become involved in trademark disputes.

\section{Underestimating Trademark Strength}

Based on Table 1, the court seems to have underestimated the strength of the asserted trademark in thirteen cases. In most of these cases, however, the underestimation of trademark strength did not cause the court's assessment of likelihood of confusion to differ from the Google shortcut described above (as explained in the footnotes for these cases).

THE SCOOTER STORE was held to be generic for a store that sells and repairs motorized scooters (and other things such as wheelchairs), ${ }^{194}$ but all ten top hits for [ "THE SCOOTER STORE" ] related to that store. This result indicates that consumers associate that phrase with the plaintiff's scooter store, rather than as a generic term for scooter stores (just as consumers use THE CONTAINER STORE for the well-known storage container store, rather than as a generic term for stores that sell containers). The court seems correct, however, that the defendant SpinLife's use of phrases such as "mobility scooter

190. Beerntsen v. Beerntsen's Confectionary, Inc., No. 11-C-151, 2012 WL 1900108, at*1, *4-5 (E.D. Wis. May 24, 2012).

191. Id. at *4.

192. See 2 MCCARTHY, supra note $1, \S 16: 34$.

193. The court seems to hold that BEERNTSEN is unprotectable in general, and not just against BEERNTSEN'S CONFECTIONARY. See Beerntsen, 2012 WL 1900108, at *4-5. This conclusion appears to be a legal error - the fact that two parties have rights to BEERNTSEN for candy in Wisconsin does not mean that they have no rights against a third party that opens a new BEERNTSEN candy store. But this mistake is an issue of law, rather than an issue of consumer perception of the BEERNTSEN mark.

194. Scooter Store, Inc. v. SpinLife.com, LLC, No. 2:10-CV-18, 2011 WL 6415516, at *9 (S.D. Ohio Dec. 21, 2011). 
store" is unlikely to cause confusion: ${ }^{195}$ [ SCOOTER STORE ] has hits for plaintiff, defendant, and multiple other scooter stores, indicating that plaintiff should have at most only a narrow range of protection in the phrase "The Scooter Store." The court was not necessarily wrong to find THE SCOOTER STORE to be generic - even a term consumers associate with a unique source is unprotectable if it is generic, ${ }^{196}$ and perhaps even THE CONTAINER STORE is generic. ${ }^{197}$ And given the problems that might arise from protecting "The Scooter Store" but not "Scooter Store," it may be preferable to limit The Scooter Store to an unfair competition cause of action. ${ }^{198}$ But "[t]he standard to be applied to determine whether a term is a generic name... [is] whether its generic meaning is its principal significance [to the public],, 199 and the search results may inform this assessment.

In other cases, the court held marks to be descriptive without secondary meaning (and thus unprotectable) despite strong Google results. While these decisions nonetheless seem correct in finding no likelihood of confusion, erroneous decisions that a mark is unprotectable will prevent a party from asserting that mark against more confusing competitors. All ten top hits for [ SINUCLEANSE ] and [ SINU CLEANSE ] were for the SinuCleanse nasal and sinus irrigation system. ${ }^{200}$ All ten top hits for [ LOVELYSKIN ] and four for [ "LOVELY SKIN"] were for LovelySkin skin care products. ${ }^{201}$ All ten top hits for [ HUDSON SKY TERRACE ] were related to the Hudson Sky Terrace (an outdoor bar space in New York City). ${ }^{202}$ All ten

195. Id. at $* 13$

196. See 2 MCCARTHY, supra note $1, \S 12: 46$.

197. Cf. Eric Goldman, Keyword Advertiser Mostly Defeats Trademark Lawsuit-Scooter Store v. SpinLife, TECH. \& MARKETING L. BlOG (Jan. 4, 2012, 9:00 AM), http://blog.ericgoldman .org/archives/2012/01/keyword_adverti_6.htm ("I've argued that all '[noun] store' marks (where the store sells the noun) are generic.").

198. Cf. Blinded Veterans Ass'n v. Blinded Am. Veterans Found., 872 F.2d 1035, 1036, 1038-39 (D.C. Cir. 1989) (holding that "Blinded Veterans Association" is generic and thus unprotectable despite the district court's finding of secondary meaning, but that the Blinded Veterans Association still had a viable passing-off claim against the Blinded American Veterans Foundation).

199. 2 MCCARTHY, supra note $1, \S 12: 6$.

200. The court found SINUCLEANSE unprotectable and thus no likelihood of confusion with the competing SINUSENSE product. Water Pik, Inc. v. Med-Sys., Inc., 848 F. Supp. 2d 1262, 1279, 1282 (D. Colo. 2012). A search for [ SINUSENSE ] yielded no hits for the SINUCLEANSE product.

201. The court ordered the cancellation of LOVELYSKIN because of lack of acquired distinctiveness and found no likelihood of confusion with the competing LIVELYSKIN.COM. Lovely Skin, Inc. v. Ishtar Skin Care Prods., LLC, No. 8:10-CV-87, 2012 WL 4711917, at*15 (D. Neb. Oct. 3, 2012). Searches for [ LIVELYSKIN ] and [ "LIVELY SKIN" ] yielded no hits for LOVELYSKIN.

202. The court found HUDSON SKY TERRACE and SKY TERRACE AT HUDSON unprotectable and thus did not need to address whether there was a likelihood of confusion with an entertainment venue in New York City, the HUDSON TERRACE. Morgans Grp. LLC v. John Doe Co., No. 10-CV-5225, 2012 WL 1098276, at*9 n.10 (S.D.N.Y. Mar. 31, 2012). Even though all of the top ten hits for [ HUDSON SKY TERRACE ], [ "HUDSON SKY TERRACE" ], and [ "SKY 
top hits for [ ISHOPSTARK ] and [ "I SHOP STARK" ] related to the iShopStark.com website for promoting businesses in Stark County, Ohio. ${ }^{203}$

There were also a number of decisions that a mark was weak (albeit protectable) despite strong Google results, although again, these decisions seem correct on the ultimate conclusion of no likelihood of confusion. For example, a court found the "wave" portion of the NU WAVE mark for the NuWave Pro Infrared Oven "merely descriptive because it refers to the infrared wave cooking feature of halogen ovens" and found no evidence of strength, ${ }^{204}$ but all ten top hits for [ NUWAVE oven ] and [ NU WAVE oven ], eight for [ NU WAVE ], and six for [ NUWAVE ] related to the NuWave Pro Infrared Oven. ${ }^{205}$ The STEAK UMM mark for frozen steak and hamburger was found to be "[n]ot [s]trong" ("at best, suggestive" with no evidence of commercial strength), ${ }^{206}$ but all of the top hits for [ STEAK UMM ] and [ "STEAK UMM" ] were related to plaintiff's product. ${ }^{207}$

Similarly, the court found it unlikely that MANGO'S TROPICAL CAFE "will be found to have strong trademark significance," 208 but all of the top hits for [ MANGO'S TROPICAL CAFE ] and [ "MANGO'S TROPICAL CAFE" ] related to this restaurant and nightclub. ${ }^{209}$ THE VILLAGES was found to be "weak" for residential real estate, ${ }^{210}$ but seven of the top hits for [ "THE VILLAGES" ] were related to plaintiff's retirement community. ${ }^{211}$

TERRACE AT HUDSON" ] were for plaintiff's Sky Terrace, none of the top hits for [ HUDSON TERRACE ] were - all ten of them related to defendant's Hudson Terrace.

203. The court found ISHOPSTARK.COM to be descriptive without secondary meaning, and therefore did not address whether there was likelihood of confusion with SHOPNSTARK.COM. Papa Ads, LLC v. Gatehouse Media, Inc., 485 F. App'x 53, 55-56 (6th Cir. 2012). A search for [ SHOPNSTARK ] had no hits for ISHOPSTARK.

204. Hearthware, Inc. v. E. Mishan \& Sons, Inc., No. 11-C-5233, 2012 WL 3309634, at *7 (N.D. Ill. Aug. 10, 2012).

205. The court found no likelihood of confusion with the SUPER WAVE oven, $i d$. at *9, and none of the hits for [ SUPER WAVE oven ] or [ SUPER WAVE ] related to the NU WAVE oven. 2012).

206. Steak Umm Co., LLC v. Steak 'Em Up, Inc., 868 F. Supp. 2d 415, 426-28 (E.D. Pa.

207. The court found no likelihood of confusion with STEAK 'EM UP, a pizza shop and grocery store in South Philadelphia. Id. at 432. None of the results for [ "STEAK EM UP" ] or [ STEAK EM ] related to STEAK UMM aside from one hit related to the lawsuit. The search [ STEAK UM ] redirected to [ STEAK UMM ].

208. Mango's Tropical Cafe, Inc. v. Mango Martini Rest. \& Lounge, Inc., 844 F. Supp. 2d 1246, 1254 (S.D. Fla. 2011).

209. The court found no likelihood of confusion between MANGO'S TROPICAL CAFE and the restaurant and bar MANGO MARTINI, id. at 1256, and none of the hits for [ "MANGO MARTINI" ] related to Mango's Tropical Cafe (and only one related to defendant's Mango Martini).

210. Holding Co. of the Villages, Inc. v. Power Corp., No. 5:11-CV-631-OC-37TBS, 2012 WL 39395, at*4 (M.D. Fla. Jan. 9, 2012).

211. The court found no substantial likelihood that plaintiff would be able to show a likelihood of confusion between its mark and VILLAGES OF LAKESIDE LANDING. Id. at *7. The only instances of search overlap between the marks were pages related to the lawsuit. See also supra note 198 and accompanying text (noting that an unfair competition cause of action might be preferable to protecting a borderline generic mark whose secondary meaning depends on starting with "THE"). 
FANCASTER was found to be descriptive and not particularly commercially strong for a website for sports fans and other fans, ${ }^{212}$ but nine of the top hits for [ FANCASTER ] related to this site. ${ }^{213}$

For the ten cases described in this Section thus far, Google and the court disagreed about trademark strength, but the difference was not outcome determinative, because the Google shortcut did not suggest a likelihood of confusion. Erroneous findings that marks are unprotectable, though, may prevent companies from asserting those marks against future competitors whose marks actually do create confusion. But in three additional cases, the court's underestimation of trademark strength may have led to an erroneous finding of no likelihood of confusion.

The first occurred when the court considered a group of marks based on the term GIGGLE for baby gear. The plaintiff claimed four marks: (1) GIGGLE HEALTHY. HAPPY. BABY.; (2) GIGGLE BETTER BASICS; (3) THE GIGGLE CRITERIA; and (4) GIGGLE. The court stated that "whatever strength those marks possess by being suggestive succumbs to the weakness evidenced by both the reputation and use of the marks." ${ }^{214}$ But all ten of the top Google hits for [ "GIGGLE HEALTHY HAPPY BABY" ], [ "GIGGLE BETTER BASICS" ], and [ "THE GIGGLE CRITERIA" ] relate to plaintiff's baby goods stores, as do five of the top hits for [ GIGGLE ] alone, suggesting that the court underestimated the strength of these marks. The court granted summary judgment for no likelihood of confusion with THE GIGGLE GUIDE (for trade information related to children's goods), ${ }^{215}$ but six of the top hits for [ "GIGGLE GUIDE" ] are related to plaintiff, not defendant, suggesting that many consumers associate defendant's mark with plaintiff's source.

Second, PAGOSA BREWING COMPANY was found to be "entirely descriptive," and even though a jury found that the mark had secondary meaning, the court expressed "doubt that, as a matter of law, the evidence was sufficient to establish that the Plaintiff's mark had acquired a secondary meaning. ${ }^{216}$ But all ten top hits for [ PAGOSA BREWING COMPANY ] and [ PAGOSA BREWING ], and nine of the top hits for [ PAGOSA beer ], related to plaintiff's company, suggesting that PAGOSA is not merely geographically descriptive for beer. The jury had found that plaintiff's mark

212. Fancaster, Inc. v. Comcast Corp., 832 F. Supp. 2d 380, 417 (D.N.J. 2011). The court found no likelihood of confusion with Comcast's FANCAST mark, $i d$. at 411, and none of the hits for [ FANCAST ] relate to FANCASTER.

213. Because the Google shortcut collapses the two prongs of the trademark strength testinherent and acquired distinctiveness - into a single distinctiveness test, it may in fact be true that FANCASTER is not commercially strong, but Google still suggests that it is a distinctive mark.

214. Giggle, Inc. v. netFocal, Inc., 856 F. Supp. 2d 625, 631 (S.D.N.Y. 2012).

215. Id. at 637 .

216. Tony's Taps, LLC v. PS Enterprises, Inc., No. 08-CV-01119, 2012 WL 1059956, at *8 n.10 (D. Colo. Mar. 29, 2012). 
was infringed by the PAGOSA PUB WORKS AND BREWPUB, but the court denied an injunction, noting that it was "unfortunate" that the defendant had "never sought a ruling on the legal sufficiency of the Plaintiff's trademark infringement claim," and stating that it "refuse[d] to invoke its discretion to impose equitable relief in service of a claim whose legal sufficiency is in considerable doubt." 217 However, two of the top hits for [ PAGOSA BREWPUB ] relate to the PAGOSA BREWING COMPANY, suggesting some likelihood of confusion.

Finally, TEXAS TOAST was found to be generic for croutons, ${ }^{218}$ even though all ten hits for [ TEXAS TOAST croutons ] and nine for [ "TEXAS TOAST" croutons ] related to the plaintiff Marzetti's New York Brand TEXAS TOAST croutons, suggesting that consumers strongly associate TEXAS TOAST croutons with Marzetti's brand, rather than using the phrase generically. The tenth hit for [ "TEXAS TOAST" croutons ] was for a new competitor, defendant's Rothbury Farms TEXAS TOAST croutons. The Sixth Circuit affirmed a judgment for the defendant of no trademark infringement based on the finding that TEXAS TOAST is generic for croutons, concluding that "Texas Toast" is generic for "a bread product that is larger than normal." ${ }^{219}$ The top hit for [ "Texas Toast" ] alone is the Wikipedia page (which does not mention croutons), ${ }^{220}$ and no commercial entity appears more than once in the top results, suggesting that "Texas Toast" is indeed generic for thick-cut bread. But the prominence of Marzetti's in the results for [ "TEXAS TOAST" croutons ] suggests that consumers generally view "Texas Toast" as indicating Marzetti's brand in the context of croutons, rather than using it to describe thick-cut croutons. This finding may mean that "Texas Toast" is generic in a single-player market for thick-cut croutons, ${ }^{221}$ although there seem to be other thick-cut croutons marketed as "large cut.,"222 But a court should make this determination with the knowledge that consumers currently associate "Texas Toast" with Marzetti's in the context of croutons.

217. Id. at *8-9.

218. T. Marzetti Co. v. Roskam Baking Co., 680 F.3d 629, 634 (6th Cir. 2012) (quoting T. Marzetti Co. v. Roskam Baking Co., No. 2:09-CV-584, 2010 WL 2162903, at *6 (S.D. Ohio May 27, 2010)).

219. Id. at 634-35. 2014).

220. See Texas Toast, WIKIPEDIA, http://en.wikipedia.org/wiki/Texas_toast (last visited Jan. 3,

221. Cf. Kellogg Co. v. Nat'l Biscuit Co., 305 U.S. 111, 116 (1938) (holding that although National Biscuit was previously the only producer of shredded wheat cereal due to its possession of patented wheat shredding technologies, the term "shredded wheat" was descriptive and could therefore be used by Kellogg after expiration of the patent).

222. See, e.g., Large Croutons, AMAZON, http://www.amazon.com $/ \mathrm{s} / \mathrm{ref}=\mathrm{nb}$ _sb_noss?url $=$ node $\% 3$ D $16321021 \&$ field-keywords $=$ large + croutons (last visited Jan. 3, 2014). As noted when discussing MICROTHIN condoms, however, there may be many generic designations for a single product. See supra note 133 and accompanying text. 


\section{Overestimating Trademark Strength}

The court seems to have overestimated trademark strength (as compared with Table 1) in ten cases. Whereas only three out of thirteen ( 23 percent) underestimations of strength could possibly be described as leading to likelihood-of-confusion errors, it appears that eight out of ten ( 80 percent) overestimations of strength led to likelihood-of-confusion errors. The other two cases are "mistakes" only in a weak sense. In one case, the court held that a reasonable jury could find FESTIVAL OF TREES worthy of protection for a particular holiday fundraiser, ${ }^{223}$ but with only two related hits it was just below the border of protection under Table 1. In the other, the defendant stipulated that MINI was a famous mark for cars, ${ }^{224}$ but only two hits for [ MINI car ] and [ MINI auto ] related to the BMW MINI. Most were related to miniature cars, an indication that BMW may not prevent "mini" from being used in this broader sense.

In the first of the eight cases in which an overestimation of trademark strength correlated with an erroneous finding of likelihood of confusion, the court found LUCKY'S to be arbitrary and strong for three restaurants in Michigan, specifically rejecting Google search results showing many other restaurants (including in Michigan) using the name LUCKY'S. ${ }^{225}$ But the three Michigan restaurants were associated with only one hit for [ LUCKY'S ] or [ LUCKY'S restaurant ]. They were associated with eight hits for their full name, [ "LUCKY'S STEAKHOUSE" ], suggesting that this is a protectable mark, but one that is not confused with the allegedly infringing LUCKY'S PUB \& GRILLE. For example, none of the hits for [ LUCKY'S PUB ] related to the steakhouses. The court thus seems to have erred in "find[ing] as a matter of law that relevant customers are likely to believe that the parties' establishments are related in some way"226 and in granting a permanent injunction against LUCKY'S PUB AND GRILL. ${ }^{227}$

223. Primary Children's Med. Ctr. Found. v. Scentsy, Inc., No. 2:11-CV-1141, 2012 WL 2357729, at*7 (D. Utah June 20, 2012). Only two of the top hits for [ FESTIVAL OF TREES ] related to the plaintiff's fundraiser for Primary Children's Medical Center in Utah. Five were for festivals at other hospitals, and three were for other festivals. The court correctly denied a preliminary injunction against the defendant (a candle maker using FESTIVAL OF TREES as a candle scent). See id. at $* 1, * 11$.

224. BMW of N. Am., LLC v. Mini Works, LLC, 463 F. App'x 689 (9th Cir. 2011) (affirming the district court); BMW of N. Am., LLC v. Mini Works, LLC, No. CV-07-1936, 2009 WL 596586 (D. Ariz. Mar. 9, 2009). The conclusion that defendant's MINI WORKS (for BMW Mini parts and services) infringed BMW's mark seems correct under the Google shortcut: [ MINI WORKS ] and [ "MINI WORKS" ] resulted in hits for BMW.

225. Lucky's Detroit, LLC v. Double L Inc., No. 09-14622, 2012 WL 219418, at *6-8 (E.D. Mich. Jan. 25, 2012).

226. Id. at $* 13$.

227. Lucky's Detroit, LLC v. Double L Inc., No. 09-14622, 2012 WL 1658455, at *4 (E.D. Mich. May 11, 2012). 
The court also went against Google results in concluding that "the Heartland mark for veterinary services is a protectible [sic] suggestive mark" and granting a preliminary injunction against the HEARTLAND SPCA, ${ }^{228}$ even though none of the top search results for [ HEARTLAND veterinary ] related to plaintiff's HEARTLAND Animal Clinic. Six of the top hits for [ HEARTLAND ANIMAL CLINIC ] related to plaintiff's business, but this full mark does not seem likely to be confused with the HEARTLAND SPCA. A search for [ HEARTLAND SPCA ] had no hits for the Animal Clinic.

Another court granted summary judgment to plaintiff Goya on its claim that defendant's use of DEL JIBARITO for ready-to-eat sweets infringed plaintiff's EL JIBARITO mark for canned vegetables. ${ }^{229}$ But none of the top hits for [ "EL JIBARITO" ] and only one for [ "EL JIBARITO" vegetables ] related to Goya's product. Eight of the top hits for [ "EL JIBARITO" canned vegetables ] related to Goya's product, suggesting that this mark is only entitled to a narrow scope of protection in the canned vegetable market.

In another case, the owner of I FIT received a default judgment against the owner of IFITNESS (where both marks were used for fitness software), indicating that the judge found that the complaint alleged a viable infringement claim. ${ }^{230}$ But the Google results suggest that I FIT might not be protectable, as only two hits for [ "I FIT" ] related to plaintiff's software, and that there is little likelihood of confusion, as none of the [ "I FIT" ] hits related to IFITNESS, and none of the [ IFITNESS ] hits related to I FIT.

A defendant making $\mathrm{T}$-shirts stating BORN TO ROCK chose not to contest that the plaintiff had a valid trademark in BORN TO ROCK for guitars or that there was not a likelihood of confusion. Instead, the defendant relied on the (rejected) argument it was not using the mark in commerce. ${ }^{231}$ The court noted that "[i]t is not the Court's role to second-guess [the defendant's] litigation strategy,"232 and the concession may not have been wise: the Google results indicate that BORN TO ROCK only seems protectable for guitars: whereas [ "BORN TO ROCK" guitar ] had five hits for the plaintiff, [ "BORN TO ROCK" ] had only one, and [ "BORN TO ROCK" Tshirt ] did not have any.

The Fifth Circuit seems to have erred in reversing a district court's finding of no likelihood of confusion between plaintiff's MISSION for Mexican food products (such as tortilla chips, salsa, and guacamole) and defendant's

228. See Heartland Animal Clinic, P.A. v. Heartland SPCA Animal Med. Clinic, LLC, 861 F. Supp. 2d 1293, 1300-01, 1306-07 (D. Kan. 2012).

229. Goya Foods, Inc. v. Orion Distribs., Inc., 916 F. Supp. 2d 177, $185-87$ (D.P.R. 2012).

230. ICON Health \& Fitness, Inc. v. Med. Prods., No. 1:10-CV-00207, 2012 WL 3962737, at *6 (D. Utah Sept. 11, 2012).

231. Born to Rock Design Inc. v. CafePress.com, Inc., No. 10 CIV. 8588 CM, 2012 WL 3954518, at*4 (S.D.N.Y. Sept. 7, 2012).

232. Id. at $* 4$ n. 3 . 
MISSION BURRITO for a chain of Houston-based Mexican restaurants. ${ }^{233}$ The court of appeals found MISSION to be arbitrary, commercially strong, and likely to cause confusion. ${ }^{234}$ Plaintiff's mark does appear to be strong for the products it sells: all ten top hits for [ MISSION tortilla chips ], six for [ MISSION salsa ], and eight for [MISSION guacamole ] relate to plaintiff's products. But plaintiff does not seem to have a protectable interest in MISSION for Mexican food in general: none of the top hits for [ MISSION Mexican ] or [ MISSION BURRITO ] and only one for [ MISSION Mexican food ] relate to plaintiff. Trademark law protects a mark owner's ability to expand into markets where it does not currently compete based on "the ordinary customer's perception of possible expansion, ${ }^{, 235}$ but if a non-expanded mark is sufficiently strong that consumers might anticipate such expansion, searches with keywords for those fields would likely still have pages related to the mark.

Finally, the most significant errors may be in two jewelry-related cases in which Google search results show no connection between the asserted mark and the plaintiff's product, even beyond the first page of search results. In one, Richmond-based Capri Jewelers claimed rights in DIAMONDS DIRECT (based on past advertisements such as "Buy Direct, Save Direct" and "Annual Direct Diamond Sale") and received a preliminary injunction against DIAMONDS DIRECT USA (a chain which had planned to open a Richmond location). ${ }^{236}$ But Google search found no websites linking DIAMONDS DIRECT with Capri Jewelers (aside from pages related to this trademark suit). ${ }^{237}$ In the other, Perfect Pearl Company claimed rights in MAJESTIC for pearl jewelry and received an injunction against MAJESTIC Pearl, ${ }^{238}$ but there was no online tie between Perfect Pearl and the MAJESTIC mark. ${ }^{239}$

233. See Gruma Corp. v. Mexican Rests., Inc., 497 F. App'x 392, 398 (5th Cir. 2012).

234. Id. at 395, 398.

235. 4 MCCARTHY, supra note $1, \S 24: 19$.

236. Diamonds Direct USA, Inc. v. BFJ Holdings, Inc., 895 F. Supp. 2d 752, 757 (E.D. Va. Oct. 2, 2012); Diamonds Direct USA, Inc. v. BFJ Holdings, Inc., No. 3:12-CV-303, 2012 WL 5473795, at *7 (E.D. Va. Nov. 9, 2012).

237. Searches included [ DIAMONDS DIRECT ], [ "DIAMONDS DIRECT" Richmond ], and [ "DIAMONDS DIRECT" Capri Jewelers ]. The parties have now reached a settlement that allows Diamonds Direct to operate its new Richmond store under its own name. See Louis Llovio, Diamonds Direct Back to Using Its Name for Henrico Store, RICHMOND TIMES-DiSPATCH (Dec. 8, 2012, 12:00 AM), http://www.timesdispatch.com/business/local/companies /diamonds-direct-back-to-using-its-name-for-henrico-store/article_73b0f239-dba7-5f78-b41e-bc9183 adac54.html.

238. Perfect Pearl Co., Inc. v. Majestic Pearl \& Stone, Inc., 887 F. Supp. 2d 519, 538-39 (S.D.N.Y. Aug. 14, 2012).

239. Searches included [ MAJESTIC Pearl], [ MAJESTIC "Perfect Pearl" ], and [ MAJESTIC Pearl Spitzer ] (because Spitzer was the last name of the founders of Perfect Pearl), and I searched deep into the Google results rather than only looking at the first page. Of course, it is possible that Perfect Pearl simply has no online presence for MAJESTIC, but it claimed to use the mark as a business name, $i d$. at 525 , and I was able to find websites about Perfect Pearl. 


\section{Right on Strength, Wrong on Likelihood of Confusion}

There were only two cases in which the court was not inconsistent with Google on trademark strength but appears to have reached the wrong result on likelihood of confusion. In the first, the court found SEACRETS to be strong for a Jamaican-themed restaurant, bar, and entertainment complex in Maryland and found a likelihood of confusion with SECRETS for resort hotel services (leading to cancelation of the SECRETS mark, punitive damages, and an injunction). ${ }^{240}$ But while SEACRETS and SECRETS sound similar, SEACRETS's strength stems from its unusual spelling - as the court noted, "SEACRETS is a coined term, combining the English words 'sea' and 'secrets,' and does not exist in the English language.",241 As noted previously, one of Google's strengths is its ability to demonstrate the actual importance of a misspelling to a consumer. ${ }^{242}$ And Google shows that consumers associated the Maryland restaurant with SEACRETS but not SECRETS: it was related to nine of the top hits for [ SEACRETS ] (confirming the court's finding of strength), but none for [ SECRETS ] or [ SECRETS restaurant ]. Google also suggests that the defendant's SECRETS is a relatively strong mark for resort hotel services that is not likely to be confused with plaintiff's SEACRETS: all of the top hits for [ SECRETS resort ] related to defendant's hotels, as did six of the top hits for [ SECRETS hotel ].

In the second such case, the court seems to have erred in the opposite direction. It found no likelihood of confusion between plaintiff Capelli New York's CAPELLI mark for clothing and accessories and defendant Cappelli Straworld's CAPPELLI mark for hats and handbags because "[t]he marks use different words that mean different things": "CAPPELLI" means "hat" in Italian and "CAPELLI" means "hair." 243 But Google suggests that these marks are highly confusing: [ CAPELLI bags ] had about five hits for CAPPELLI bags; [ CAPELLI hats ] had about three hits for CAPPELLI hats; and one of the top hits for both [ CAPELLI bags ] and [ CAPPELLI bags ] was a shopping website that labeled bags as "Capelli of New York," even though a comparison with the Capelli New York and Cappelli Straworld catalogs indicated that these were actually Cappelli Straworld products. For some products, I was unable to determine whether they were CAPELLI or CAPPELLI products even after extensive online researchan example of actual confusion in a consumer exercising greater-than-average care. I would argue that these Google search results are strong evidence that

240. Coryn Group II, LLC v. O.C. Seacrets, Inc., 868 F. Supp. 2d 468, 484-500 (D. Md. 2012).

241. Id. at 485 .

242. See supra notes 77-78 and accompanying text.

243. GMA Accessories, Inc. v. Dorfman-Pac. Co., No. 11 CIV. 3731 KBF, 2012 WL 5462660 , at *1, *4-5 (S.D.N.Y. Nov. 5, 2012). The court did not bother to analyze the strength of either mark. 
consumers do not view these marks as distinguishable and are likely to be confused between the marks.

III.

IMPLICATIONS

\section{A. Search Results as Probative Evidence}

The results of Part II help confirm the argument that courts should give more weight to Google search evidence in trademark disputes. In the majority of cases, the search results were simply consistent with the court's conclusion. More importantly, when the court and Google disagreed, the search results suggest that the court generally misunderstood how consumers perceived the marks at issue. The few exceptional cases, in which the court reached the correct conclusion but Google did not, illustrate that the Google shortcut cannot recognize the legally permissible concurrent use of confusingly similar trademarks ${ }^{244}$ - this nuance of trademark law is best addressed by judges' expert authority rather than Google's algorithmic authority. But as explained in Part I, Google's algorithmic authority is preferable to judicial intuition for questions that depend on the wisdom of the crowds, and the Google results indicate that courts erred in their assessment of trademark strength in a number of cases. Notably, overestimation of the strength of the asserted mark seems particularly likely to lead to errors in the likelihood-of-confusion analysis.

To be sure, there is no metric for objectively correct results in trademark disputes, so in arguing that Google often does better than judicial intuition at evaluating trademarks, there is no yardstick to point to besides one's own intuition. But my own (subjective) belief is that the rough description of how Google's algorithm works (from Part I) coupled with the examples of how Google search results compare with real trademark results (from Part II) are convincing evidence that search-engine results are highly probative.

For parties and judges who are similarly convinced, the results of Part II suggest a procedure for evaluating marks in future trademark disputes. Suppose the senior mark is WACKY for red widgets, and it alleges infringement by WONKY for blue widgets. ${ }^{245}$ The typical analysis would involve noting that the marks differ by only two letters and that they are both used for widgets, but this would reveal little about how consumers perceive these marks. The Google shortcut suggests first searching for [ WACKY ] alone - if most of the hits on the first page relate to WACKY red widgets, this is a strong mark. If not, try [ WACKY widgets ] and [ WACKY red widgets ] to determine whether WACKY is a strong mark within one of these fields, or whether it is

244. See supra notes 182-93 and accompanying text.

245. Google indicates that "Wacky Widgets" and "Wonky Widgets" are actual product names, but I am using them in a hypothetical sense. 
even protectable. (And if "widget" is synonymous with "gizmo," one should confirm that making this substitution in search terms yields similar results.) If two or fewer top hits for [ WACKY red widgets ] relate to WACKY red widgets, this suggests that WACKY is merely descriptive for widgets without secondary meaning, or at most that it is a very weak mark. If the scope of protection for WACKY extends only to red widgets, this suggests that confusion with WONKY blue widgets is unlikely.

In contrast, if WACKY is a strong mark for widgets in general, the next step should be to determine the likelihood of confusion between [ WACKY widgets ] and [ WONKY widgets ]. The search results for [ WONKY widgets ] should be examined for references to WACKY widgets alone (not comparisons with WONKY), and the results for [ WACKY widgets ] should be examined for references to WONKY widgets. Any such results overlap would suggest that the marks are less distinctive from each other. Extensive overlap, such as pages where it is difficult to tell whether the widgets are from WACKY or WONKY, would suggest a higher likelihood of confusion.

The court should also evaluate other relevant factors that Google cannot capture, such as the junior user's intent in selecting a mark. If there is some search-results overlap between the marks, then one's opinion on whether a court should find infringement will depend on one's theory of trademark law. Whatever the theory, though, an understanding of the extent of this overlap should guide the court's analysis. ${ }^{246}$ And if there is no overlap, then it seems unlikely that consumers will be sufficiently confused to create infringement liability, whatever one's understanding of the goals of trademark law.

An important caveat, mentioned in the MICROTHIN and TEXAS TOAST cases discussed in Part II, is that courts should be wary of relying on Google results when assessing the protectability of a descriptive or potentially generic term for a unique product, such as a patented product with temporary market power. For example, the Supreme Court held that "shredded wheat" was generic and that the exclusive manufacturer of Shredded Wheat cereal (National Biscuit) could not prevent Kellogg from using this term to market a competing cereal after the patents on the original Shredded Wheat expired. ${ }^{247}$ Undoubtedly, had Google existed before the introduction of Kellogg's competing cereal, all of the top results for [ SHREDDED WHEAT ] would have been related to National Biscuit's product because it was the only such product that existed-but this does not mean that "shredded wheat" was not generic. While Google might inform the court about how consumers currently view a mark, it cannot assess the impact of protecting that mark on other goals,

246. See supra notes 29-35 and accompanying text.

247. Kellogg Co. v. Nat'1 Biscuit Co., 305 U.S. 111, 117-18 (1938). 
such as increasing competition or the free flow of commercial information. ${ }^{248}$ Assessing the importance of these speech-protective goals in a given case remains an important role for judicial wisdom.

Search-engine results could, however, provide strong evidence of genericide of an initially distinctive mark. Genericide occurs when consumers appropriate a mark as the name of a product, rather than viewing it as identifying source, as occurred for terms including "aspirin," "cellophane," and "escalator." 49 For determining whether a mark has become generic, "majority usage controls." ${ }^{, 50}$ None of the cases described in Part II involved allegations of genericide, but after I collected my data, Tiffany \& Co. sued Costco for using the TIFFANY mark when selling engagement rings, and Costco responded that "Tiffany is a generic term for ring settings comprising multiple slender prongs extending upward from a base to hold a single gemstone."251 While the facts regarding how Costco used "Tiffany" in advertising its rings have not yet been developed, the search results for [ TIFFANY setting ] provide some support for Costco's argument that Tiffany is generic as applied to ring settings. The first page of results included a Wikipedia page that defined "Tiffany mount" as "a common setting for a diamond solitaire engagement ring," 252 an article explicitly stating that "'Tiffany setting' has reached 'Kleenex status'-it's now used colloquially throughout the jewelry industry to describe any multi-pronged solitaire setting, Tiffany or no,"253 and an article stating that "[m]ost jewelers carry a version of this enduring classic." ${ }^{, 254}$ Only four of the top ten hits clearly used "Tiffany" to refer to Tiffany \& Co. rather than in a generic sense. ${ }^{255}$

Searches for famous examples of marks that have fallen victim to genericide further illustrate Google's potential to provide evidence of whether consumers tend to use a term generically, rather than as a mark. For example,

248. Cf. Ramsey, supra note 133 (arguing that descriptive marks should be eliminated from trademark protection to promote competition and free speech).

249. See 2 MCCARTHY, supra note $1, \S 12: 1$.

250. Id. § 12:6.

251. Answer and Counterclaim at 7, Tiffany \& Co. v. Costco Wholesale Corp., No. 13 Civ. 1041 (S.D.N.Y. Mar. 8, 2013). The district court recently denied Tiffany's motion for summary judgment on Costco's counterclaim, concluding that there is "a genuine factual dispute as to whether the terms 'Tiffany' and/or 'Tiffany Setting' have a primarily generic meaning in the minds of members of the general public in the context of ring settings." Tiffany \& Co. v. Costco Wholesale Corp., No. 13 Civ. 1041, 2014 WL 199603, at *5 (S.D.N.Y. Jan. 17, 2014).

252. Tiffany Mount, WIKIPEDIA, http://en.wikipedia.org/wiki/Tiffany_mount (last visited Jan. $3,2014)$.

253. Jane Lee, Deconstructing The Tiffany Setting, The World's Most Popular Engagement Ring, FORBES (Oct. 2, 2012, 5:58 PM), http://www.forbes.com/sites/janelee/2012/10/02 /deconstructing-the-tiffany-setting-the-worlds-most-popular-engagement-ring-style.

254. Erika W., Tiffany Inspired -Tiffany Setting Comparison, PRICESCOPE (Dec. 28, 2010), http://www.pricescope.com/blog/tiffany-inspired-tiffany-setting-comparison.

255. Searches were performed on March 13, 2013, with the search location as both "United States" and "New York, NY." Only four of the top ten hits clearly used "Tiffany" to refer to Tiffany \& Co. rather than in a generic sense. 
only two of the top ten hits for [ aspirin ] used the term to refer to the product made by Bayer (the original brand owner); the other eight used it generically, and two of them referred to Bayer's loss of trademark rights. All of the top hits for [ cellophane ] appeared to use the term generically, rather than to refer to cellophane made by the original brand owner Innovia Films (although the About.com page on the history of cellophane stated that Cellophane is a registered trademark of Innovia in the United Kingdom). Similarly, all of the top hits for [ escalator ] used the term generically, rather than to refer to escalators made by Otis Elevator Company, though two of the hits mentioned Otis in the history of the escalator. ${ }^{256}$ Search results reveal whether most users searching for a term are looking for a particular source or whether they are looking for a product in general, and these results are thus highly probative as to whether a mark has become generic.

The results in Part II were based on Google searches performed at one point in time (shortly after each judicial decision) and for one location for each mark, but practitioners submitting search-engine results in actual cases should use multiple search engines on multiple dates with multiple location settings (for example, comparing the results in local cities with the results for the whole United States). Saving search results is easy and inexpensive, and as discussed in more detail in Part III.0, showing that results are consistent over time will alleviate concerns about intentional gaming of search results. Ideally, very early search results would show whether the senior user of a descriptive mark achieved secondary meaning before the junior user's first use ${ }^{257}$ parties in trademark disputes should begin saving search results as early as possible, especially where priority is contested. Search results saved over time (such as every few months) could be used to demonstrate that consumer perception of a mark has remained constant and that the results are not a temporary fluke due to deceptive search-engine optimization or due to a new user that did not initially appear in the results. Unfortunately, it is not currently possible to retrieve the Google results from a given date in the past (although Google itself has reconstructed past versions of the index on a couple of occasions). ${ }^{258}$

As discussed in Part I.C, search-engine evidence is admissible in trademark disputes, so no legal change is required. Courts simply need to recognize why search-engine evidence is highly probative in trademark disputes and to start according much greater weight to this evidence when it is submitted. When the parties fail to submit search-engine evidence, the court

256. These Google searches were performed on February 8, 2013, with the search location set to "United States."

257. See generally 2 MCCARTHY, supra note $1, \S 16: 34$ (discussing how to achieve priority in secondary meaning marks).

258. E-mail from Google software engineer to author (Dec. 12, 2011, 11:30 AM) (on file with author); see, e.g., Google Search 2001, GOOGLE, http://www.google.com/search2001.html (last visited Jan. 3, 2014) ("From September 29 to October 31, 2008, this page allowed you to search the Google index of 2001.”). 
may conduct its own Google search and take judicial notice of the results. ${ }^{259}$ Courts might also eventually choose to draw an adverse inference from the failure to offer search evidence, or to hold that search evidence can create a presumption of strength or of invalidity. The other party could rebut with other search-engine results (such as by showing that the results are inconsistent across time, location, or search engine) or with strong traditional evidence (such as a survey). Once courts understand what the Google search results are in a given case and why they are relevant, they can evaluate whether there is some case-specific reason that the Google shortcut would not work.

\section{B. Using Google To Test New Marks}

The Google approach described so far is only directly effective for marks that are actually in use in commerce. But the Patent and Trademark Office (PTO) often must evaluate unused marks based on intent-to-use applications to determine whether they are "merely descriptive" or "likely... to cause confusion," 260 and Google can still provide probative evidence in making these evaluations. Indeed, although courts have been reluctant to rely on search results, the TTAB is considering such evidence more frequently, ${ }^{261}$ although this acceptance is not uniform. ${ }^{262}$ Search results can indicate whether the proposed mark is frequently used to describe the relevant products or services

259. Cf. McCormack v. Hiedeman, 694 F.3d 1004, 1008 n.1 (9th Cir. 2012) (taking judicial notice of a Google Maps search); Conn. Cmty. Bank v. The Bank of Greenwich, 578 F. Supp. 2d 405, 415 (D. Conn. 2008) ("The court conducted a series of Google searches on the final day of trial, February 19, 2008, of which it takes judicial notice and copies were provided to the parties."); FED. R. EVID. 201 (stating that "[t]he court may judicially notice [an adjudicative] fact that is not subject to reasonable dispute because it ... can be accurately and readily determined from sources whose accuracy cannot reasonably be questioned," and that the court "may take judicial notice on its own" and "at any stage of the proceeding" as long as any "party is entitled to be heard on the propriety of taking judicial notice"). For a discussion of potential concerns with judicial fact finding at the Supreme Court, which is also relevant to other appellate courts, see Allison Orr Larsen, Confronting Supreme Court Fact Finding, 98 VA. L. REV. 1255 (2012).

260. See 15 U.S.C. $§ 1052$ (2012) (describing a trademark application and stating that trademarks "shall be refused registration" if, among other reasons, the mark is "likely, when used on or in connection with the goods of the applicant, to cause confusion" or "merely descriptive").

261. See, e.g., In re Ryw Enters., LLC, 2012 WL 6137601, at *2 (T.T.A.B. Nov. 27, 2012) (noting that search results for [ RANGOON ] "included three websites referring to "Crab Rangoon"" and thus supported the Board's conclusion that CRAB RANGOON is merely descriptive); In re Langham, $2012 \mathrm{WL} 4832273$, at *5 (T.T.A.B. Sept. 30, 2012) (citing Google results in finding "xxx dvd rentals" to be generic); In re Oakton Press, Inc., 2011 WL 3381371, at *3 (T.T.A.B. July 19, 2011) (citing Google results for [ "consumer affairs"] in finding CONSUMERAFFAIRS.COM to be generic).

262. See, e.g., Rolex Watch U.S.A., Inc. v. PRL USA Holdings, Inc., 2012 WL 2588574, at *7 (T.T.A.B. June 7, 2012) (finding a Google image search for [ RLX watch ] to have little probative value as to whether consumers associate RLX with Rolex because it is just "one search engine using the abbreviation rlx" and "there is no information as to how many U.S. customers have been exposed to this usage"); In re SMS Holdings Corp., 2011 WL 1399226, at *1 n.1 (T.T.A.B. Mar. 25, 2011) ("The examining attorney [at the PTO] also submitted copies of Google Internet search results, which by nature are of minimal probative value and are not necessary to our decision herein."). 
(suggesting that the mark is merely descriptive) or whether there are already similar products or services using similar marks.

For example, a mark with zero hits - known as a "Googlenope"263 - is surely arbitrary or fanciful and therefore relatively unlikely to cause confusion with any existing marks. Current examples (which will no longer be Googlenopes once this Article is indexed) include ZARVENAX and PERIDOT WOMBAT. ${ }^{264}$ Marks are also likely to have high inherent distinctiveness and to be unlikely to be found similar to existing marks if they generate few Google hits for commercial products or services; for example, FLYING FUNGUS has about nine thousand hits and PANTSMASTER has about thirty thousand, but neither has any significant commercial presence, suggesting that these are also promising choices for strong new marks.

The field of the mark is also relevant: LIGHT BULB is generic for light bulbs, but my search for [ "LIGHT BULB" restaurant ] only has links about the use of light bulbs in restaurants, rather than using "light bulb" to describe restaurants or in the names of restaurants, suggesting that THE LIGHT BULB would be a highly distinctive name for a restaurant. And Google allows one to quickly determine that LIGHT BULB is far more distinctive for a restaurant than the similarly arbitrary HORSESHOE, which appears to be the name of independent restaurants in at least ten different states.

\section{Responding to Objections}

In addition to the concerns courts have raised when considering Google and other search-engine results, which were critiqued in Part I.C, there are a number of other possible objections to the Google shortcut. This Section responds to five such concerns. As discussed further below, all of these concerns will be alleviated by (1) considering results from multiple search engines on multiple dates with multiple location settings and (2) remembering that parties can rebut search-engine evidence with traditional forms of evidence in cases where Google does not accurately reflect how consumers perceive a mark.

The first potential concern is that Google search is essentially a black box: the public knows relatively little about the algorithm that produces its search results. ${ }^{265}$ But we know enough about the algorithm to support the theoretical inference that Google results are probative in trademark cases. We know that

263. About Googlenopes, GOOGLENOPE.COM, http://googlenope.com/about.php (last visited Nov. 25, 2012).

264. Searches were performed on November 25, 2012. Single-word Googlenopes such as ZARVENAX will always be fanciful; PERIDOT WOMBAT is arbitrary for everything unrelated to green or gem-like marsupials. Note that Google is also useful for suggesting the closest existing marks: a search for [ ZARVENAX ] results in Google asking, "Did you mean: ZRAVEX ZRAVIANX SERVINOX [or] ZARVOX[?]"

265. Cf. Pasquale, supra note 81 , at $244-48$ (calling for more transparency in search-engine algorithms). 
Google generally provides sites related to what users search for (which it has profit-based incentives to do) and that it evaluates algorithm changes based on whether the change increases the frequency with which users click on the top search results. Algorithmic details are not really helpful without understanding how these details are related to the relevance of results for users-which Google knows based on running experiments on users every time they search. If one could peer inside the black box, it would be more important to confirm that Google evaluates algorithms the way it claims, rather than to know the details of the algorithm itself. And as discussed in Part I.B, even if Google were intentionally skewing results toward Google products (the typical accusation of search-engine bias), this would not affect the use of Google results as trademark evidence because it involves replacing one site referring to a trademark (such as Yelp) with another (such as Google+). ${ }^{266}$ In practice, parties should compare results across multiple search engines, and courts should be more skeptical of Google results that are vastly different from results from Bing or Yahoo. Courts should also be aware of changes in search-engine technology: in the future, search results may need to be interpreted differently, or they may cease to be useful evidence.

A second concern is that there is no such thing as "Google results" in an era of increasingly personalized and highly time-variant search. As discussed above, Google requires a search location so it can provide more relevant local results (although this location can be set to "United States"), ${ }^{267}$ though localized results may actually be helpful in trademark disputes where local perceptions are relevant. Google results can also differ from user to user based on search personalization: a signed-in user will see customization based on search history, Google+ connections, or cookies stored on a machine, ${ }^{268}$ but Google allows personalized search to be disabled. ${ }^{269}$ As noted above, the searches described in Part II were performed in incognito mode in the Chrome browser, which also reduces personalization concerns. ${ }^{270}$ Even with careful

266. See supra notes 87-90 and accompanying text.

267. See supra note 120 and accompanying text.

268. See Turn Off Search History Personalization, GoOGLE, https://support.google.com /accounts/bin/answer.py?hl=en\&answer $=54048$ (last visited Jan. 3, 2014) (explaining how personalized search results can be disabled).

269. Id . If these non-personalized searches eventually show results that few actual searchers see in practice, it might pose a problem (or it might simply show the "average" understanding of a mark in a useful way), but when I compared personalized and non-personalized searches for the trademarks I studied, I never found significant differences. Eventually, personalized search may lead to a form of non-geographic trademark localism, in which a mark has secondary meaning for certain types of people, and parties may want to experiment with whether search results are different with certain personalizations. But for now, I recommend that courts rely on non-personalized search.

270. See supra note 123 and accompanying text; see also Mark Traphagan, Going Incognito for Better SEO Testing, G PLUS SEO (Mar. 20, 2012), http://gplusseo.net/post/47 ("You can go 'incognito' to try to de-personalize your results as much as possible."). Google's public information is not entirely clear about whether incognito searches consider already-existing cookies on your 
choice of search location and elimination of search personalization, the same search might yield different results due to Google's frequent experiments with algorithm tweaks. ${ }^{271}$ But these experiments are generally focused on complicated parsing issues that only affect a small percentage of searches, such as the ability to recognize [ mike siwek lawyer $\mathrm{mi}$ ], rather than basic searches for brand names. ${ }^{272}$

To test the robustness of the Google shortcut to localized search and to changes in search results over time, I ran every search described in this Article again on January 20, 2013, using both the original search location (the city of the district judge who heard the case) and a location of "United States." but two cases there was either no change or only minor changes in the number of top hits related to one of the parties, but not enough to change the outcomes described above. ${ }^{274}$ In the other two cases, a search that previously only had one hit for the plaintiff (suggesting that the mark was insufficiently distinctive for protection) had four (suggesting the mark might be protectable, albeit weak): [ "ALL METAL" ] had four hits for All Metal Sales, Inc., and [ LUCKY'S restaurant ] had four hits for Lucky's Steakhouse. ${ }^{275}$ In both cases, however, the search had only one hit for the plaintiff when the search location was changed to "United States." These were also the only cases where there was a significant difference between the localized search and the "United States" search, illustrating the importance of checking results for multiple search locations. ${ }^{276}$ And in both cases, the results still contained no overlap between plaintiff's and defendant's marks (aside from some results

computer, see Turn Off Search History Personalization, supra note 268, so cautious searchers might want to also clear their cookies before searching. See Traphagan, supra.

271. See Susan Snipes, Reasons Your Google Search Results are Different than Mine, META Q (Apr. 3, 2012), http://themetaq.com/articles/reasons-your-google-search-results-are-different-than -mine.

272. See Levy, supra note 67.

273. In future research, it would be valuable to compare the results of Google and other search engines such as Bing for a variety of trademarks.

274. For example, Kimono condoms were related to five (not three) hits for [ MICROTHIN ] alone; Unleashed Doggie Day Care was related to zero hits (not one hit) for [ UNLEASHED dogs ]; [ SPIDER THREAD fishing line ] had five (not four) hits for defendant (but still two for plaintiff); the luxury bag company was related to six (not two) hits for [ $\mathrm{COACH}]$ (but still none for [ $\mathrm{COACH}$ testing ]); LovelySkin was related to nine (not four) hits for [ "LOVELY SKIN" ] (plus one related to the lawsuit); the Giggle baby goods stores were related to seven (not five) hits for [ GIGGLE ]; and Pagosa Brewing Company was related to five (not two) hits for [ PAGOSA BREWPUB ].

275. For the earlier discussions of these cases, see supra notes 141, 225-27 and accompanying text. In the ALL METAL case, the court concluded that "[w]hile[] the evidence referred to by Plaintiff could certainly provide an inference of secondary meaning and/or likelihood of confusion, it was by no means dispositive in a legal sense"- a conclusion that is not clearly wrong even with the new search results. All Metal Sales, Inc. v. All Metal Source, LLC, No. 1:10 CV 2343, 2012 WL 1831235, at *3 (N.D. Ohio May 18, 2012).

276. In most cases, the two searches were identical or involved only minor reordering of search results. In a few cases, the two searches had different results, but those differences did not affect the Google shortcut. 
related to the lawsuit in the ALL METAL case), suggesting that even if the marks are protectable, there is still not a likelihood of confusion. Overall, the possibility of robustness checks like this alleviates concerns that search results will be too highly dependent on search location or search date to be useful. In any individual case, if the search results are somehow highly affected by personalization, then results from different dates (or from the opposing party) should show this inconsistency.

A third concern is that the Google shortcut will hurt small businesses. For example, one might worry that businesses without a web presence will be harmed. But as discussed in Part I.B, Google can accurately reflect consumer perceptions of trademarks that do not have their own websites: most serviceoriented businesses have reviews on sites such as Yelp, most products are available on eBay, and many marks are mentioned in news stories or blog posts. $^{277}$ One might also worry about larger companies increasingly using cease-and-desist letters against small businesses who interfere with their Google results-or even specious lawsuits against Google itself over result placement. This is an important concern, but widespread adoption of the Google shortcut could actually reduce the costs of trademark litigation by making it faster and cheaper to evaluate trademark claims. And the results in Part II suggest that courts are currently more likely to err on the side of finding confusion where none exists, suggesting that the Google shortcut may actually protect the speech of small businesses.

A fourth concern is that heavier reliance on Google results will create incentives for companies to manipulate results through deceptive search-engine optimization. Of course, not all search-engine optimization is a cause for concern: as Google has explained, "white hat" optimization-techniques focused on helping users rather than deceiving search algorithms - "can be positive and constructive" by helping searchers find the most relevant content, which would only improve the content of search results for trademark purposes. ${ }^{278}$ But some companies attempt to promote the search rankings of sites that are not relevant to users, and thus not reflective of how consumers perceive marks, through deceptive "black hat" techniques. ${ }^{279}$

277. I tried and failed to think of a mark that is used in commerce but that I could not find on Google.

278. Cutts, supra note 63; see Search Engine Optimization (SEO), GoOGLE, http://support.google.com/webmasters/bin/answer.py?hl=en\&answer=35291 (last visited Jan. 3, 2014) (providing advice on good search-engine optimization practices and a link to Google's Search Engine Optimization Starter Guide).

279. Black-hat techniques include computer-generated content, link schemes (such as paying for links or excessive cross-linking), and cloaking (causing a website to present different content to search engines and human users). See Webmaster Guidelines, GOOGLE, http://support.google.com /webmasters/bin/answer.py?hl=en\&answer=35769 (last visited Jan. 3, 2014) (describing these and other prohibited optimization practices). 
There is little reason to think, however, that using Google results in trademark disputes will significantly alter the enormous incentives companies already have to promote their Google rankings - or the incentives Google has to thwart these techniques to ensure that users continue to be presented with the most relevant results. As James Grimmelmann has explained, search-engine optimization "is as much a fixture of the Internet as spam.... Websites compete fiercely, and not always ethically, for readers," and "much, indeed most, of the time, the real alliance is between search engines and users, together trying to sort through the clamor of millions of websites' sales pitches.",280

Furthermore, most search-engine optimization does not affect the relevance of Google results in trademark disputes. The results of searches for generic terms, such as [ sneakers ], are of great interest to sneaker companies but irrelevant to the Google shortcut. And while Zappos, Amazon, and Foot Locker might compete fiercely for the highest ranking in a search for [ ADIDAS ], ${ }^{281}$ all of them use ADIDAS to refer to the sneaker company and are thus equivalent for showing that ADIDAS is a strong mark. It would be more concerning if Adidas used black-hat search-engine optimization techniques to get most of the top results for [ NIKE ] to refer to the goddess of victory rather than Adidas's competitor, but as long as most users searching for [ NIKE ] are indeed trying to find NIKE shoes and athletic products, it seems likely that Google will continue to deliver these more relevant results. "Google bombing" efforts - in which many website owners make a concerted effort to raise the ranking of a site for some search phrase by linking to the site using that phrase-have generally targeted only individual pages using keywords without trademark significance, ${ }^{282}$ and have become more difficult

280. Grimmelmann, supra note 85 , at $446,459$.

281. For example, they might create many links using "Adidas" as "anchor text" that links to their own websites. But Google has deemphasized the role of "boiler plate links with duplicated anchor text" in determining rankings because this tool is often used to promote irrelevant results. See Matt Cutts, Ten Recent Algorithm Changes, GoOgle Inside SEARCH (Nov. 14, 2011, 8:30 AM), http://insidesearch.blogspot.com/2011/11/ten-recent-algorithm-changes.html ("We found that boilerplate links with duplicated anchor text are not as relevant, so we are putting less emphasis on these.”); Danny Goodwin, Google Penguin Update: Impact of Anchor Text Diversity \& Link Relevancy, SEARCH ENGINE WATCH (May 6, 2012), http://searchenginewatch.com/article/2172839 /Google-Penguin-Update-Impact-of-Anchor-Text-Diversity-Link-Relevancy (describing Google's efforts to demote sites with aggressive anchor text).

282. See Google Bomb, WIKIPEDIA, http://en.wikipedia.org/wiki/Google bomb (last visited Jan. 3, 2014) (listing examples such as linking "miserable failure" to President George W. Bush's official biography or "more evil than Satan himself" to Microsoft). There was a campaign to remove GoDaddy from the top hit for [ "domain registration" ], see id., but even if this had been successful it would not have affected GoDaddy's trademark strength, which would have required altering the results for searches containing "GoDaddy" rather than for searches for generic terms. Note again that high-ranking pages that use a mark to criticize the mark owner, such as killercoke.org (a site criticizing Coca-Cola's labor practices that is currently on the first page of results for [ $\mathrm{COKE}]$ ), do not hurt the mark owner under my test. 
due to Google's algorithm changes. ${ }^{283}$ And even if Adidas did succeed in a massive Google bombing campaign to drive Nike off the first page of results for [ NIKE ], Nike could rebut this Google evidence by providing traditional evidence of trademark strength, or by obtaining evidence of Adidas's deceptive practices through discovery.

A fifth and final concern is that even if Google's algorithmic authority is preferable to judicial intuition and subjective multifactored tests to determine how consumers perceive trademarks, Google results still may not be perfectly aligned with the legal issues in trademark law. Heavier reliance on Google search might lead Google to colonize these legal issues, so that our understanding of trademark law shifts toward Google rankings. As a comparative example, although ranking law review articles by citations is cheap, easy, a reasonable proxy for importance, and less prone to certain kinds of bias than more subjective evaluations, the proliferation of these rankings ${ }^{284}$ has shifted the legal academy's understanding of a "good" article toward one that receives many citations in a way many legal scholars might find disturbing. ${ }^{285}$ Similarly, one might be concerned about increasing reliance on algorithmic authority and computerized legal determinations in fields outside trademark law, ${ }^{286}$ as is already occurring in many agencies. ${ }^{287}$

But the key distinction between trademark law and agency decisions or law review rankings is that article quality and most legal concepts are the kinds

283. See Ryan Moulton \& Kendra Carattini, A Quick Word About Googlebombs, GoOGLE WeBMASTER CENTRAL BlOG (Jan. 25, 2007, 4:16 PM), http:/googlewebmastercentral.blogspot .com/2007/01/quick-word-about-googlebombs.html; Danny Sullivan, Google Kills Bush's Miserable Failure Search \& Other Google Bombs, SEARCH ENGINE LAND (Jan. 25, 2007, 11:00 PM), $\mathrm{http} / / /$ searchengineland.com/google-kills-bushs-miserable-failure-search-other-google-bombs-10363.

284. See, e.g., Fred R. Shapiro \& Michelle Pearse, The Most-Cited Law Review Articles of All Time, 110 Mich. L. ReV. 1483 (2012); Brian Leiter, Most Cited Law Professors by Specialty, 2000 2007, BRIAN LEITER's L. SCH. RANKINGS (Dec. 18, 2007), http://www.leiterrankings.com /faculty/2007faculty impact areas.shtml; Brian Leiter, Top 70 Law Faculties in Scholarly Impact, 2007-2011, BRIAN LEITER’S L. SCH. RANKINGS (July 2012), http://www.leiterrankings.com/new /2012_scholarlyimpact.shtml.

285. See J.M. Balkin \& Sanford Levinson, How to Win Cites and Influence People, 71 CHI.KENT L. REV. 843, 846 (1996); Shapiro \& Pearse, supra note 284, at 1485 (mentioning the use of citations in tenure decisions).

286. Cf. Betsy Cooper, Judges in Jeopardy!: Could IBM's Watson Beat Courts at Their Own Game?, 121 YALE L.J. ONLINE 87 (2011) (suggesting that a computer could be used for statutory interpretation); Harry Surden, The Variable Determinacy Thesis, 12 COLUM. SCI. \& TECH. L. REV. 1, 3 (2011) ("As early as the seventeenth century, Gottfried Leibniz, the great mathematician and coinventor of calculus, speculated that legal liability might be derivable through calculation. Since that time, this notion - that legal determinations might be "calculable" and perhaps automatable - has continued to intrigue scholars in the computer science domain.").

287. See Danielle Keats Citron, Technological Due Process, 85 WASH. U.L. REV. 1249, 1252 (2008) (describing the increasing use of automated decision making for determining welfare benefits, purging voters from registries, excluding people from air travel, and instituting child support collection proceedings); see, e.g., Jason Parkin, Adaptable Due Process, 160 U. PA. L. REV. 1309, 1357 (2012) ("In some welfare agencies, computers are . . . actually deciding who receives benefits and in what amounts."). 
of questions that depend on expert wisdom, whereas the main questions in trademark law are, by definition, based on the wisdom of the crowds. As noted in the nascent literature on legal citations to Wikipedia, consensus-based websites can be "appropriate source[s] when the wisdom of the crowd is valuable on its own." 288 Even if search results can never perfectly capture public perception (just as no survey results could), the goals of Google are still aligned with the goal in trademark law of understanding mark distinctiveness. So while the move from reliance on expert authority to algorithmic authority might be cause for concern in many fields, trademark law is the kind of field that benefits from this move. I do not claim that Google is (or will always be) the best source of algorithmic authority for trademark law, or that my methodology for analyzing search results could not be improved. ${ }^{289}$ Also, as noted above, judicial wisdom is still necessary to evaluate issues such as whether a word is being used as a mark, what Google searches are appropriate, and whether recognizing trademark rights in a mark would conflict with the First Amendment or other values. But I hope to have at least convinced the reader that search results can be useful in trademark disputes, especially if one understands both their benefits and their limitations.

\section{CONCLUSION}

I have argued in this Article that U.S. courts are wrong to discount online search evidence in trademark infringement cases. But I do not want to overstate my claim. My study is "empirical" only in a loose sense of the term, in that I show how Google results compare with the actual results in eighty-eight cases. Due to the flaws in current methods of evaluating trademarks, I am not using these cases as a baseline against which to measure Google. I do not know of any commentators who think courts always err, however, so it is reassuring that in most cases, Google and the courts agree. The more interesting cases are those in which the court's opinion is inconsistent with Google, for which I argue that Google better reflects consumer perceptions of the marks at issue. As noted above, one cannot prove that the Google shortcut is objectively better

288. Jason C. Miller \& Hannah B. Murray, Wikipedia in Court: When and How Citing Wikipedia and Other Consensus Websites Is Appropriate, 84 ST. JoHN's L. REV. 633, 646 (2010); see also Lee F. Peoples, The Citation of Wikipedia in Judicial Opinions, 12 YALE J.L. \& TECH. 1, 31 (2010) (stating that Wikipedia is "a good source for definitions of new slang terms, for popular culture references, and for jargon and lingo").

289. There are many other algorithmic sources that capture consumer sentiments about trademarks to varying degrees, such as Twitter followers, Facebook "likes," or Alexa rankings of website traffic. These examples seem less useful than Google results because they reveal nothing about uses of the mark by third parties, but they seem more useful than marketing expenditures because they require affirmative actions by consumers. They also might be more useful than Google for measuring commercial strength independently, as Google can only measure a mark's total strength (both inherent and acquired distinctiveness). Combining data from various algorithmic sources might lead to better information about trademarks than looking at search results alone, but I leave the defense of these other tools to future work. 
than actual outcomes, both because there is no objective measure of the correct results in trademark disputes, and because the Google shortcut itself involves some subjective choices. I argue, however, that a theoretical understanding of how Google works coupled with the many case studies of how Google results apply in actual cases provide convincing evidence that these results are in fact highly probative of trademark distinctiveness and better reflect consumer perceptions of the marks at issue.

My narrowest claim is that Google and other online search results can serve a function similar to survey data for evaluating distinctiveness where time or cost constraints make it infeasible to conduct a survey. And even when such constraints are less important, Google results have the advantage over surveys of being less manipulable and more replicable. My broader claim is that Google results can supplant a significant portion of current trademark strength and likelihood-of-confusion inquiries. But one does not need to be convinced by this broader claim in order to accept the narrower claim.

Finally, while this Article has focused on U.S. trademark law, these results have international implications. The TRIPS agreement requires that in all WTO member countries, "[a]ny sign . . . capable of distinguishing the goods or services of one undertaking from those of other undertakings, shall be capable of constituting a trademark," and "[t]he owner of a registered trademark shall have the exclusive right to prevent ... [use of similar signs for similar goods] where such use would result in a likelihood of confusion."290 Google has a larger market share in many other countries than it does in the United States, ${ }^{291}$ so it may be possible to directly translate the protocol suggested here to other jurisdictions as long as the results are interpreted in light of the applicable legal framework. ${ }^{292}$ And even where Google is not dominant, these results could be translated to other online services that are generally successful at finding what consumers are looking for when they type a given word or phrase.

290. Agreement on Trade-Related Aspects of Intellectual Property Rights arts. 15-16, Apr. 15, 1994, Marrakesh Agreement Establishing the World Trade Organization, Annex 1C, 1869 U.N.T.S. 299, 306 (1994).

291. Compare Goodwin, supra note 60 (stating that Google's U.S. market share is around 70 percent), with NETMARKETSHARE, supra note 60 (reporting that Google has about 80 percent of the global search market).

292. For example, trademark rights in the European Union and most other countries stem from registration of the mark, not use in commerce. See 3 MCCARTHY, supra note 1, § 19:1.75; Kelly Lee, A Comparison of the US and EU Mark Registration Systems, 19 J. CONTEMP. LEGAL ISSUES 423, 426 (2010). 
[Vol. 102:351 